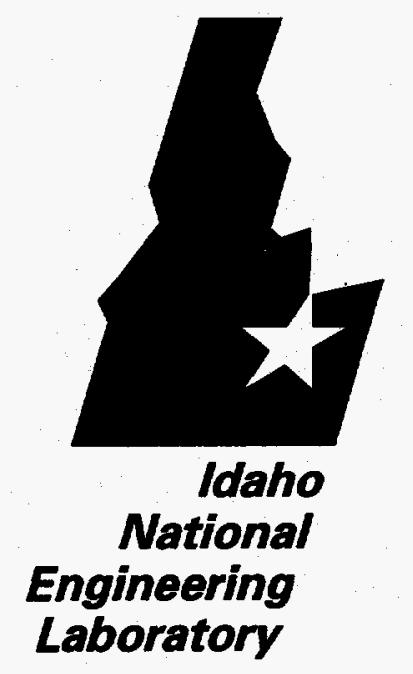

\title{
MELCOR Aerosol
} Transport Module

APR 17 Bges

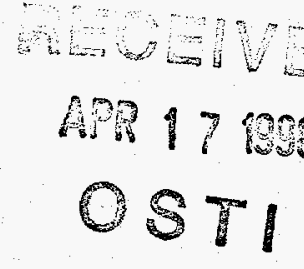
Modification for NSSR-1
B. J. Merrill
D. L. Hagrman 


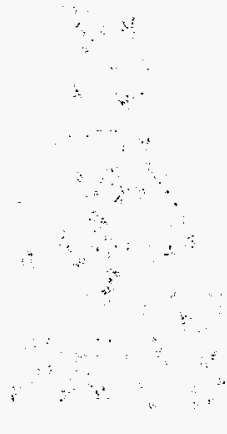

.

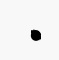

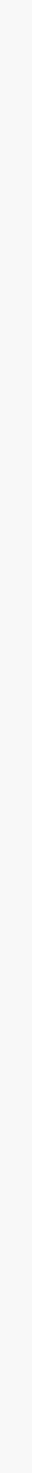


INEL-96/0081

ITER/US96/TE/SA-03

\title{
MELCOR Aerosol Transport Module Modification for NSSR-1
}

\author{
B. J. Merrill \\ D. L. Hagrman
}

Published March 1996

Idaho National Engineering Laboratory

Lockheed Idaho Technologies Company Idaho Falls, Idaho 83415

Prepared for the

U.S. Department of Energy

Office of Fusion Energy

Under DOE Idaho Operations Office

Contract DE-AC07-94ID13223 



\begin{abstract}
This report describes modifications of the MELCOR computer code aerosol transport module that will increase the accuracy of calculations for safety analysis of the International Thermonuclear Experimental Reactor (ITER). The modifications generalize aerosol deposition models to consider gases other than air, add specialized models for aerosol deposition during high speed gas flows in ducts, and add models for resuspension of aerosols that are entrained in coolants when these coolants flash. Particular attention has been paid to the adhesion of aerosol particles once they are transported to duct walls. The results of calculations with the modified models have been successfully compared to data from Light Water Reactor Aerosol Containment Experiments (LACE) conducted by an international consortium at Hanford, Washington.
\end{abstract}

\title{
DISCLAIMER
}

\begin{abstract}
This report was prepared as an account of work sponsored by an agency of the United States Government. Neither the United States Government nor any agency thereof, nor any of their employees, makes any warranty, express or implied, or assumes any legal liability or responsibility for the accuracy, completeness, or usefulness of any information, apparatus, product, or process disclosed, or represents that its use would not infringe privately owned rights. Reference herein to any specific commercial product, process, or service by trade name, trademark, manufacturer, or otherwise does not necessarily constitute or imply its endorsement, recommendation, or favoring by the United States Government or any agency thereof. The views and opinions of authors expressed herein do not necessarily state or reflect those of the United States Government or any agency thereof.
\end{abstract}





\section{EXECUTIVE SUMMARY}

The potential for transport of activated material as aerosols is a consideration in the safety analysis for the International Thermonuclear Experimental Reactor (ITER). In order to support the analysis, a number of modifications to the MELCOR computer code aerosol transport module have been completed. The modifications generalize aerosol deposition models to consider gases other than air, add specialized models for aerosol deposition during high speed gas flows in ducts, and add models for resuspension of aerosols that are entrained in coolants when these coolants flash. Particular attention has been paid to the adhesion of aerosol particles once they are transported to duct walls.

We have benchmarked these modifications against data from experiments conducted by the Electric Power Research Institute (EPRI) designated as large-scale light water reactor (LWR) aerosol containment experiments (LACE) and found excellent agreement. For high speed flows in pipes, our model predicts that $\widetilde{-3 \%}$ of the aerosol mass entering the LACE test pipe remains on the pipe walls in comparison with a measured value for LACE test CB3 of $1 \%$. When we extend our surface adhesion model to include gravitational settling, the predicted pipe aerosol mass retention drops to $1.2 \%$. If the deposited aerosol films are highly viscous, as was the case for LACE test LA1, our model predicts that $98.4 \%$ of the aerosol mass entering the LACE test pipe will remain on the pipe wall. The measured aerosol mass retention was reported as greater than $98 \%$. We have found good agreement between our model and the data from the LACE containment depressurization test, LA5. MELCOR predicted pressures and temperatures that are within $6 \%$ of those measured by this test. In addition, the peak concentration of aerosol re-suspended as a result of pool flashing was predicted to reach $0.58 \mathrm{mg} / \mathrm{m}^{3}$ compared to a measured value of $0.48 \mathrm{mg} / \mathrm{m}^{3}$.

However, even given the success of this benchmarking exercise, there are still some unanswered issues with respect to our modified MELCOR aerosol transport module. These issues primarily center around aerosol chemical characteristics and carrier gas conditions of the LACE experiments being different than those expected in ITER, and the accuracy of some of the LACE measurements. As a consequence, we suggest that additional aerosol transport tests be performed to obtain data more characteristic of ITER accident conditions, and to improve the confidence level we have in our aerosol transport module. 



\section{ACKNOWLEDGMENTS}

The authors gratefully acknowledge Dr. Hans-Werner Bartels, who is in charge of the system level thermal-chemical Code 3 task for his support for this work. Also, we wish to thank Frank Rahn of the Electric Power Research Institute (EPRI) for providing documents about the light water reactor (LWR) aerosol containment (LACE) experiments.

The authors wish to thank their colleagues, most notably Dave Petti, and Kathy McCarthy, for their comments and critiques of this report. 



\section{CONTENTS}

ABSTRACT $\ldots \ldots \ldots \ldots \ldots \ldots \ldots \ldots \ldots \ldots \ldots \ldots \ldots \ldots \ldots \ldots \ldots \ldots \ldots \ldots \ldots$, ii

EXECUTIVE SUMMARY $\ldots \ldots \ldots \ldots \ldots \ldots \ldots \ldots \ldots \ldots \ldots \ldots$ iii

ACKNOWLEDGMENTS $\ldots \ldots \ldots \ldots \ldots \ldots \ldots \ldots \ldots \ldots \ldots \ldots \ldots \ldots \ldots \ldots \ldots \ldots$

1. INTRODUCTION $\ldots \ldots \ldots \ldots \ldots \ldots \ldots \ldots \ldots \ldots \ldots \ldots \ldots \ldots \ldots \ldots \ldots \ldots$

2. IMPROVEMENTS TO MELCOR AEROSOL DEPOSITION

COEFFICIENTS $\ldots \ldots \ldots \ldots \ldots \ldots \ldots \ldots \ldots \ldots \ldots \ldots \ldots, 2$

3. NEW AEROSOL DEPOSITION MODELS $\ldots \ldots \ldots \ldots \ldots \ldots \ldots \ldots$

3.1 Turbulence Deposition Model $\ldots \ldots \ldots \ldots \ldots \ldots \ldots \ldots \ldots \ldots$

3.2 Pipe Bend Inertial Deposition Model $\ldots \ldots \ldots \ldots \ldots \ldots \ldots \ldots$

3.3 Surface Adhesion Model $\ldots \ldots \ldots \ldots \ldots \ldots \ldots \ldots \ldots . \ldots 9$

4. LIQUID ENTRAINED AEROSOL RE-SUSPENSION MODEL . . . . . . 13

5. COMPARISON OF AEROSOL DEPOSITION MODELS TO LACE DATA . 18

5.1 LACE Containment Bypass Tests $\ldots \ldots \ldots \ldots \ldots \ldots \ldots \ldots \ldots .18$

5.2 MELCOR Results for LACE Containment Bypass Tests .......... 21

5.3 LACE Containment De-pressurization Tests .............. 22

5.4 MELCOR Results for LACE Containment De-pressurization Tests .... 23

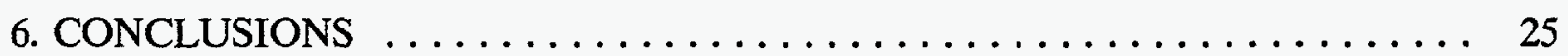

7. REFERENCES $\ldots \ldots \ldots \ldots \ldots \ldots \ldots \ldots \ldots \ldots \ldots \ldots \ldots \ldots \ldots \ldots \ldots \ldots \ldots \ldots$

Appendix A. Estimate of Properties of Materials in LACE Tests $\ldots \ldots \ldots$ A1

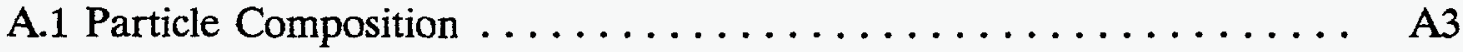

A.2 Condensed Phase Densities $\ldots \ldots \ldots \ldots \ldots \ldots \ldots \ldots \ldots$ A7

A.3 Surface Tension of Condensates $\ldots \ldots \ldots \ldots \ldots \ldots \ldots \ldots$ A8

A.4 Viscosities of Condensates $\ldots \ldots \ldots \ldots \ldots \ldots \ldots \ldots \ldots \ldots \ldots \ldots \ldots \ldots \ldots \ldots$

A.5 Appendix A References . . . . . . . . . . . . . . . . A11

Appendix B. Listing of FORTRAN Coding for Modifications of MELCOR .... B1 



\section{INTRODUCTION}

We have completed modifications to the MELCOR code $^{1}$ aerosol transport module that will increase the accuracy of this module for International Thermonuclear Experimental Reactor (ITER) safety analyses of accidents like loss-of-cooling accidents (LOCAs) into the vacuum vessel. These accidents will re-suspend material eroded from the first wall and divertor, and corrosion products in ITER's heat transport system (HTS) coolant. The modifications described in this engineering design file (EDF) document address aerosol deposition in gases other than air, turbulence and inertial aerosol deposition for high speed flows in ducts, and re-suspension of aerosols that are entrained in coolants when these coolants flash. Most of these modifications were proposed in an assessment of the MELCOR code performed in $1994,{ }^{2}$ and undertaken in 1995 after revising ITER Joint Central Team (JCT) Task Agreement S 81 TT 03 9502028 FU, subtask 2, entitled: System Level Transient Thermal-Chemical Codes. These revisions were made because of changes in research and development (R\&D) priorities prompted by results from the Early Safety and Environmental Characterization Study (ESECS).

In the following section of this EDF, we address the changes that were made to the aerosol module of the MELCOR code to account for carrier gases that are not air. Section 3 presents the theory for two new aerosol deposition models that were added to the MELCOR code. These models predict the aerosol deposition rates produced by momentum gained by an aerosol particle from turbulence in a carrier gas and by centrifugal forces produced when the carrier gas flows around a pipe bend. Section 4 of this EDF describes a model that has been developed for the MELCOR code that resuspends aerosols entrained in a liquid coolant back into the atmosphere when this liquid flashes to a vapor. In Section 5, we describe a series of test that were conducted by the Electric Power Research Institute (EPRI) designated as large-scale light water reactor (LWR) aerosol containment experiments (LACE). These tests examined the transport of aerosols typical of LWRs through pipes with high speed flow and in containment volumes during rapid de-pressurization. We also present in Section 5 a comparison between data from these tests and our new MELCOR aerosol transport module. Finally, Section 6 contains conclusions drawn from this model development task. 


\section{IMPROVEMENTS TO MELCOR AEROSOL DEPOSITION COEFFICIENTS}

Aerosol deposition on structures by MELCOR occurs as a result of four mechanisms: thermophoresis, gravity, diffusion, and diffusiophoresis. ${ }^{3}$ The equations used to define the rate at which the first three mechanisms occur involve thermal-physical properties of the carrier gas. The equations that define the velocity at which aerosols deposit are as follows:

$$
\begin{gathered}
u_{g}=\frac{\rho_{p} g d^{2} C}{18 \mu \chi} \\
u_{T}=\frac{3 \mu C\left[c_{t} K n+k_{g} / k_{s}\right] \nabla T}{2 \times \rho_{g} T\left[1+3 c_{m} K n\right]\left[1+2 C_{t} K n+2 k_{g} / k_{s}\right]} \\
u_{D}=\frac{D}{\Delta_{D i f f}}
\end{gathered}
$$

where

$\mathrm{u}_{\mathrm{g}} \quad=$ deposition speed from gravitational settling $(\mathrm{m} / \mathrm{s})$

$\mathrm{u}_{\mathrm{T}}=$ deposition speed from thermophoresis $(\mathrm{m} / \mathrm{s})$

$\mathrm{u}_{\mathrm{D}}=$ deposition speed from diffusion $(\mathrm{m} / \mathrm{s})$

$\mathrm{c}_{\mathrm{m}} \quad=$ particle slip coefficient

$c_{\mathrm{s}} \quad=$ particle sticking coefficient

$\mathrm{c}_{\mathrm{t}} \quad=$ thermal accommodation coefficient

$\mathrm{C}=$ particle mobility $(\mathrm{s} / \mathrm{kg})$

$\mathrm{d} \quad=$ particle diameter $(\mathrm{m})$

$\mathrm{D}=$ diffusion coefficient $\left(\mathrm{m}^{2} / \mathrm{s}\right)$

$\mathrm{k}_{\mathrm{g}} / \mathrm{k}_{\mathrm{s}}=$ ratio of thermal conductivity of the gas to that for the particle

$\mathrm{Kn}=$ Knudsen number, ratio of gas molecule mean free path to particle radius

$\mathrm{T}=$ temperature $(\mathrm{K})$

$\rho \quad=$ density $\left(\mathrm{kg} / \mathrm{m}^{3}\right)$

$\mu \quad=$ viscosity $(\mathrm{kg} / \mathrm{m}-\mathrm{s})$

$\chi \quad=$ dynamic shape factor

$\Delta_{\text {Diff }}=$ diffusion boundary layer thickness (m)

As can be seen from these Equations 1 through 3, gas properties of density, viscosity, conductivity, and particle diffusivity are required by these equations. The standard 
MELCOR model assumes that the carrier gas is air. In addition, these deposition velocities are calculated once at the start of a MELCOR calculation for four sets of pressure and temperature values. These four sets are used with linear interpolation techniques to rapidly evaluate the velocities as a function of time during the MELCOR calculation. This approach, while very time efficient, would not be accurate for gases other than air. We have modified MELCOR to calculate these aerosol deposition coefficients by using the time-dependent properties of the gas that actually exits during a given calculation, for example steam, hydrogen, air, helium, etc. or mixtures thereof. The Fortran coding for the required modifications to the MELCOR code are contained in Appendix B.

Comparison of calculation results before and after this revision shows excellent agreement near the temperatures, pressures, and composition (air) used as a basis for the standard MELCOR deposition model. For points away from the basis points, ten to twenty percent differences were found for all aerosol deposition mechanisms in air except thermophoresis. The thermophoresis deposition rates differed by as much as $80 \%$. Of course, gases like hydrogen which have viscosities and densities greatly different than air would have correspondingly larger differences. From this we conclude that the deposition processes other than thermophoresis are approximately linear. 


\section{NEW AEROSOL DEPOSITION MODELS}

Two new aerosol deposition models have been added to the MELCOR code. These models address the particle deposition mechanisms produced by fluid turbulence in pipes and particle centrifugal forces in pipe bends. These deposition mechanisms are shown schematically in Figure 1. In the case of turbulent deposition (Figure 1a), a particle suspended in a fluid flowing in a pipe obtains momentum from the fluid in both the parallel and perpendicular direction to flow. The perpendicular momentum is gained from fluid turbulence. Since the particle density is larger than the fluid density, this momentum will allow the particle to penetrate the buffer layer and viscous sublayer of turbulent flow that are adjacent to the pipe surface and to impact this same surface. When a fluid flows around a pipe bend, particles that are suspended in this fluid experience a centrifugal force that radially accelerates these particles, causing them to impact the pipe wall (Figure 1b). This process is called inertial deposition. However, even in the event of surface impact produced by either deposition mechanism, surface forces must be large enough to overcome the momentum associated with these particles if these particles are to adhere permanently to this surface. In the following three subsections, we present models for turbulence deposition, inertial deposition, and surface adhesion. The Fortran coding for the required modifications to the MELCOR code are contained in Appendix B.

\subsection{Turbulence Deposition Model}

We have adopted a model proposed by Wood ${ }^{4}$ for aerosol deposition in pipes as a result of fluid turbulence. This model is semi-empirical, and is derived by solving a diffusion equation written in the form of a turbulent version of Fick's law, which is

$$
N=\left(D_{p}+\varepsilon\right) \frac{d c}{d y}
$$

where

$\mathbf{N}=$ particle flux $\left(\# / \mathrm{m}^{2}-\mathrm{s}\right)$

$D_{p}=$ particle diffusion coefficient $\left(\mathrm{m}^{2} / \mathrm{s}\right)$

$\varepsilon=$ particle turbulent eddy-diffusivity $\left(\mathrm{m}^{2} / \mathrm{s}\right)$

c = particle concentration $\left(\# / \mathrm{m}^{3}\right)$

$\mathrm{y}=$ distance from surface $(\mathrm{m})$

Equation 4 can be written in a non-dimensional form as follows

$$
\frac{N}{c_{o} u_{*}}=V_{+}=\left(\frac{D_{p}}{\nu}+\frac{\varepsilon}{\nu}\right) \frac{d c_{+}}{d y_{+}}
$$

where

$c_{0}=$ particle concentration in turbulent core of the flow

$\mathrm{c}_{+}=\mathrm{c} / \mathrm{c}_{\mathrm{o}}$ 


$$
\begin{aligned}
& V_{+}=\text {non-dimensional deposition velocity } \\
& \nu=\text { fluid kinematic viscosity }\left(\mathrm{m}^{2} / \mathrm{s}\right)
\end{aligned}
$$

The fluid friction velocity of Equation 5 is defined as

$$
u_{*}=\sqrt{\tau_{o} / \rho}=u_{f} \sqrt{f_{f} / 2}
$$

where $f_{f}$ is the dimensionless friction factor used to predict pressure losses in turbulent fluid flow, and where $u_{\mathrm{f}}$ is the fluid velocity at the center of the pipe. We have adopted the following Blauis' formula, as did Wood, for flow in a smooth tube as the expression for this friction factor

$$
f_{f}=\frac{0.0797}{R e^{1 / 4}}
$$

where $\operatorname{Re}\left(=\mathrm{u}_{\mathrm{f}} \mathrm{D} / \nu\right)$ is the Reynolds number for fluid flow.

Integrating Equation 5 over the boundary layer associated with turbulent fluid flow gives the desired non-dimensional deposition velocity $\left(V_{+}\right)$. To accomplish this integration, Wood introduces the following standard expressions for the turbulent eddy diffussivity in the viscous sublayer

$$
\left(\frac{\varepsilon}{\nu}\right)_{S}=\left(\frac{y_{+}}{14.5}\right)^{3} \quad\left(0 \leq y_{+} \leq 5\right)
$$

and in the buffer layer

$$
\left(\frac{\varepsilon}{\nu}\right)_{B}=\frac{y_{+}}{5}-0.959 \quad\left(5 \leq y_{+} \leq 30\right)
$$

respectively. Separating variables and integrating Equation 5 gives

$$
\frac{1}{V_{+}} \int_{0}^{1} d c_{+}=\int_{y_{+}^{0}}^{y_{+}^{\infty}} \frac{\nu d y_{+}}{D_{p}+\varepsilon}
$$

This equation can be written in two parts as 


$$
V_{+}=\frac{1}{\left(I_{S}+I_{B}\right)}
$$

where

$$
I_{S}=\int_{y_{+}^{0}}^{y_{+}^{i}} \frac{\nu d y_{+}}{\left(D_{p}+\varepsilon\right)_{S}}
$$

and

$$
I_{B}=\int_{y_{+}^{i}}^{y_{+}^{*}} \frac{\nu d y_{+}}{\left(D_{p}+\varepsilon\right)_{B}}
$$

The solution of Equation 12, upon substitution of Equation 8, becomes

$$
I_{S}=\frac{14.5}{\left(D_{p} / \nu\right)^{2 / 3}}\left[f(\phi)+g(\phi)-f\left(\phi_{1}\right)-g\left(\phi_{1}\right)\right]
$$

where

$$
\begin{aligned}
& f(\phi)=\frac{1}{6} \ln \frac{(1+\phi)^{2}}{1-\phi+\phi^{2}} \\
& g(\phi)=\frac{1}{\sqrt{3}} \tan ^{-1}\left(\frac{2 \phi-1}{\sqrt{3}}\right) \\
& \phi=\frac{y_{+}^{i}}{a} ; \phi_{1}=\frac{y_{+}^{0}}{a} ; a=14.5\left(\frac{D_{p}}{\nu}\right)^{1 / 3}
\end{aligned}
$$

The solution of Equation 13, upon substitution of Equation 9 and assuming $\varepsilon>D_{p}$, becomes 


$$
I_{B}=5 \ln \left(\frac{y_{+}^{\infty}-4.8}{y_{+}^{i}-4.8}\right)
$$

Wood defines the lower limit of integration for Equation 13 as

$$
y_{+}^{0}=s_{+}+b_{+}
$$

which equals the sum of the non-dimensional particle stopping distance and the nondimensional effective surface roughness. This implies that a particle must diffuse though the buffer layer, and possibly partially though the viscous sublayer, to a height above the pipe surface from which the particle's perpendicular momentum will allow the particle to reach the pipe surface. The upper limit of integration $\left(y_{+}{ }^{i}\right)$ for Equation 12 equals 5, which also equals the lower limit for Equation $13\left(\mathrm{y}_{+}{ }^{\mathrm{i}}\right)$. However, when $\mathrm{y}_{+}{ }^{0}$ becomes greater than $5, I_{s}$ equals zero, and the lower limit of integration for $I_{b}$ becomes $y_{+}{ }^{0}$. The upper limit of integration for $\mathrm{I}_{\mathrm{b}}\left(\mathrm{y}_{+}{ }^{\circ}\right)$ is taken as equal to 30 .

The non-dimensional perpendicular stopping distance of Equation 16 is defined as

$$
s_{+}=u_{\perp} t_{p_{+}}
$$

where the non-dimensional particle relaxation time equals

$$
t_{p_{+}}=\left(\frac{B \rho_{p} d_{p}^{2}}{18 \rho \nu}\right) \frac{u_{*}}{\nu}
$$

This particle relaxation time is a measure of the time required by a particle to reach its terminal velocity when a force is applied to it. The perpendicular particle velocity of Equation 17 is that velocity gained from turbulent eddy motion and is defined as

$$
u_{\perp}=A u_{*}
$$

The coefficient $\mathrm{A}$ of this equation was found by Wood to be 0.69 by matching aerosol deposition data for a hydraulically smooth tube (i.e. $b_{+}$equal to zero). For roughened tubes, Wood uses the following expression for the non-dimensional surface roughness

$$
b_{+}=0.45 e \frac{u_{*}}{\nu}
$$

where "e" is the surface roughness height $(\mathrm{m})$.

Wood proposes Equation 11 for calculating the non-dimensional particle deposition 
velocities for non-dimensional relaxation times of less than 10 . For relaxation times that are greater than 20 , Wood proposes the following expression

$$
V_{+}=A\left[\sqrt{\frac{2}{\pi}} \operatorname{erfc}\left[\frac{1}{\sqrt{2}}\left(1+\frac{b_{+}}{s_{+}}\right)\right]\right.
$$

We have adopted a log-linear interpolation with respect to particle relaxation time for the transition between Equations 11 and 21. Once the non-dimensional deposition velocity is determined for these equations, the actual particle deposition velocity for turbulence is

$$
V_{t}=V_{+} u_{*}
$$

This deposition mechanism is applied to both solid (i.e. pipe walls), and liquid (i.e. pool) surfaces in our model.

\subsection{Pipe Bend Inertial Deposition Model}

To calculate the inertial deposition of aerosols in pipe bends, we start with the centrifugal force acting on the particle as the fluid turns a pipe bend. This force is given by

$$
F_{c}=\frac{\pi}{6}\left(\rho_{p}-\rho_{f}\right) d_{p}^{3} \frac{u_{f}^{2}}{r_{b}} \approx m_{p} \frac{u_{f}^{2}}{r_{b}}
$$

where

$$
\begin{aligned}
& \mathrm{d}_{\mathrm{p}}=\text { particle diameter }(\mathrm{m}) \\
& \mathrm{u}_{\mathrm{f}}=\text { fluid velocity }(\mathrm{m} / \mathrm{s}) \\
& \mathrm{r}_{\mathrm{b}}=\text { bend radius of pipe }(\mathrm{m}) \\
& \rho_{\mathrm{p}}=\text { particle density }\left(\mathrm{kg} / \mathrm{m}^{3}\right) \\
& \rho_{\mathrm{f}}=\text { fluid density }\left(\mathrm{kg} / \mathrm{m}^{3}\right) \\
& \mathrm{m}_{\mathrm{p}}=\text { particle mass }(\mathrm{kg})
\end{aligned}
$$

The terminal velocity in the radial direction that a particle will obtain as a result of this force is given by

$$
u_{p_{\perp}}=B F_{c}
$$

where " $\mathrm{B}$ " is the particle mobility defined as 


$$
B=\frac{1}{\left(3 \pi \mu_{g} d_{p}\right)}
$$

where $\mu_{\mathrm{g}}$ is the carrier gas viscosity. The time that it will take for a particle to travel around a bend is given by

$$
t_{b}=\frac{r_{b} \Theta_{b}}{u_{f}}
$$

where $" \Theta_{b}$ " is the pipe turning angle in radians. Consequently, the radial distance a particle will drift during in this turn is the product of bend travel time and the particle radial velocity, which becomes

$$
s=\Theta_{b} B m_{p} u_{f}
$$

when Equation 23 is used to express the centrifugal force. By assuming a well mixed particle concentration in the pipe $\left(c_{o}\right)$, the fraction of particles that will collide with the wall in the bend is approximately the radial drift distance divided by the pipe diameter (i.e. $\mathrm{s} / \mathrm{D})$. The particle flux $\left(\# / \mathrm{m}^{2}-\mathrm{s}\right)$ for inertial deposition based on this collided fraction, when averaged over the pipe surface area, can be expressed as

$$
\Gamma_{i}=\frac{s}{D} \frac{c_{o} u_{f} A_{c}}{A_{s}}
$$

where

$\mathrm{D}=$ pipe diameter $(\mathrm{m})$

$A_{c}=$ pipe cross-sectional area $\left(\mathrm{m}^{2}\right)$

$A_{s}=$ pipe surface area $\left(\mathrm{m}^{2}\right)$

The deposition velocity associated with this particle flux is as follows

$$
V_{i}=\frac{\Gamma_{i}}{c_{o}}
$$

This deposition mechanism applies only to solid surfaces in our model.

\subsection{Surface Adhesion Model}

When a particle impacts a given surface, adhesive surface and film drag forces act on this particle, as illustrated in Figure 2. If this particle is to adhere to this surface, these forces must be of sufficient strength to overcome the incident momentum of this particle as it reflects off of a surface. The adhesive forces include both a capillary force 
associated with a surface film, if present, and the Van der Waals force. An expression for these forces is as follows ${ }^{5,6}$

$$
F_{a}=4 \pi r_{p} \sigma+\frac{3}{2} \pi r_{p} \gamma f_{R}
$$

where

$\sigma=$ surface tension of possible film on surface $\left(\mathrm{J} / \mathrm{m}^{2}\right)$

$\gamma=$ surface energy per unit area for Van der Waals interaction $\left(\mathrm{J} / \mathrm{m}^{2}\right)$

$f_{R}=$ surface energy reduction factor due to surface roughness

Reeks $^{6}$ suggests that the surface energy for Van der Waals interaction $(\gamma)$ typically varies between 0.04 to $0.2 \mathrm{~J} / \mathrm{m}^{2}$, and that surface roughness reduces this energy density by at least an order of magnitude (e.g. $f_{R} \leq 0.1$ ). The viscous drag force experienced by a particle from a liquid film on a surface can be expressed as follows

$$
F_{d}=\frac{3}{2} \pi r_{p} \mu_{f} u
$$

where $\mu_{\mathrm{f}}$ is the viscosity of the liquid surface film.

Given Equations 30 and 31, the minimum momentum that a particle must have after a perfectly elastic collision with a surface to escape surface adhesive forces is

$$
m_{p} u_{c}=\int_{0}^{t} F_{s} d t=\int_{0}^{t_{a}} F_{a} d t+\int_{0}^{t_{d}} F_{d} d t \approx F_{a} t_{a}+F_{d} t_{d}
$$

where

$\mathrm{u}_{\mathrm{c}}=$ critical escape velocity $(\mathrm{m} / \mathrm{s})$

$\mathrm{m}_{\mathrm{p}}=$ particle mass $(\mathrm{kg})$

$\mathrm{t}_{\mathrm{a}}=$ surface adhesion time $(\mathrm{s})$

$t_{\mathrm{d}}=$ film residence time (s)

We define the time-interval over which surface forces will act on a particle as the distance over which a force acts on a particle divided by the velocity of the particle. For the surface adhesion forces, Reeks suggests that the distance over which particles will be influenced by these forces is on the order of magnitude of the particle radius. Therefore, the time-interval for surface adhesion equals the particle radius divided by the particle critical escape velocity $\left(t_{a}=r_{p} / u_{c}\right)$. For the viscous drag force, the time-interval approximately equals twice the film thickness divided by the critical escape velocity $\left(t_{d}=2 \delta / u_{c}\right)$. With these definitions, the particle critical escape velocity can now be evaluated by combining Equations 30,31 and 32 . The result is a quadratic equation which when solved for the desired velocity gives 


$$
u_{c}=\frac{3 \pi r_{p} \mu_{f} \delta_{f}}{2 m_{p}}+\sqrt{\left(\frac{3 \pi r_{p} \mu_{f} \delta_{f}}{2 m_{p}}\right)^{2}+\frac{\pi r_{p}^{2}}{m_{p}}\left(4 \sigma+\frac{3}{2} \gamma f_{R}\right)}
$$

where $\delta_{\mathrm{f}}$ is the film thickness.

Particles that impact a surface will have both a perpendicular and parallel velocity component with respect to this surface. Given the deposition velocities from the turbulence and inertial deposition models as the perpendicular particle velocity (i.e. Equations 22 and 24), the parallel velocity of a particle that possesses enough momentum to escape the surface forces can be obtained from

$$
u_{1}=\sqrt{u_{c}^{2}-u_{\perp}^{2}}
$$

Particles with parallel velocities greater than this velocity will ricochet back into the boundary layer, and perhaps even back into the turbulent core, of the carrier gas.

Knowing the critical parallel velocity allows us to predict the distance above a surface at which particles will have this velocity based on standard universal velocity profiles. ${ }^{7}$ For turbulent flow, the non-dimensional height (i.e. $\mathrm{y}_{+}=\mathrm{yu}_{*} / \nu$ ) above a surface can be related to the non-dimensional fluid velocity (i.e. $u_{+}=q / u_{*}$ ) as follows

$$
y_{+}=e^{\left(u_{+}+3.05\right) / 5} \quad\left(5 \leq u_{+} \leq 14\right)
$$

for the buffer layer, and

$$
y_{+}=u_{+} \quad\left(0 \leq u_{+} \leq 5\right)
$$

for the viscous sublayer. As illustrated in Figure 3, all particles that are within $s_{+}$(the non-dimensional particle stopping distance) of a given surface, but are further away from this surface than $y_{+}{ }^{c}$ will possess enough momentum to escape the surface forces. All particles within a distance of $y_{+}{ }^{c}$ from this surface will not have enough momentum to escape the surface forces. Therefore, the fraction of the particles that strike a surface and adhere (e.g. surface adhesion factor) can be found by taking the ratio of these two non-dimensional heights, that is 


$$
s_{a}=\frac{\min \left(y_{+}^{c}, s_{+}\right)}{s_{+}}
$$

The product of this adhesion factor and the deposition velocity (i.e. Equations 11 or 24 , and 37) results in the effective deposition velocity for our turbulence and inertial deposition models on solid surfaces. 


\section{LIQUID ENTRAINED AEROSOL RE-SUSPENSION MODEL}

During either normal operation or accident conditions in ITER, particulate will become entrained in the coolant of the ITER HTS. The particulate entrained during normal operation are corrosion products from pipe walls of the HTS. The particulate entrained during accident conditions, such as a LOCA into the vacuum vessel, are dust from first wall and divertor surface erosion. Because this coolant can be superheated with respect to ambient conditions, coolant flashing could occur. The model developed in this section addresses the issue of re-suspension of this particulate into the atmosphere during coolant flashing.

The present MELCOR model assumes that once aerosol particles become entrained in the liquid phase of the coolant, these particles remain in the liquid until an arbitrarily small quantity of liquid remains. After this point, the entrained aerosol mass is linearly re-suspended in proportion with the liquid mass that flashes. This could become a very non-conservative assumption if the aerosol re-suspension occurs after the aerosol carrier gas has lost its impetus to transport these aerosols.

Our new model re-suspends the liquid entrained aerosols into vapor bubbles generated by the flashing process. Once inside these bubbles, these aerosols re-deposit on the liquid surface of the bubbles by the aerosol deposition mechanisms of Brownian diffusion, gravitational settling, and inertial impaction. These bubbles eventually rise to the surface where the aerosols are released into the atmosphere. This approach is very similar to pool scrubbing models developed for codes like MELCOR. ${ }^{3}$ Therefore, we have adapted the existing MELCOR pool scrubbing model as a basis for our liquid entrained aerosol re-suspension model. The Fortran coding for the required modifications to the MELCOR code are contained in Appendix B.

Our re-suspension model starts with an integral solution to an aerosol conservation of mass equation written for a bubble, assuming no sources of aerosol mass. This equation relates the aerosol mass that reaches the pool surface to the aerosol mass in a carrier gas that enters the bottom of a pool and forms a bubble as follows

$$
m_{a}=m_{a_{o}} \exp \left(-\int V_{b}^{-1} \int u_{d} d A_{b} d t\right)
$$

where

$\mathrm{m}_{\mathrm{a}}=$ bubble aerosol mass $(\mathrm{kg})$

$\mathrm{V}_{\mathrm{b}}=$ bubble volume $\left(\mathrm{m}^{3}\right)$

$\mathbf{u}_{\mathbf{d}}=$ total aerosol deposition velocity $(\mathrm{m} / \mathrm{s})$

$A_{b}=$ bubble surface area $\left(\mathrm{m}^{2}\right)$

$\mathbf{t}=$ bubble residence time in pool (s) 
The total deposition velocity of Equation 38 is defined as

$$
u_{d}=u_{g}+u_{i}+u_{B}
$$

where

$\mathrm{u}_{\mathrm{g}}=$ gravitational settling velocity $(\mathrm{m} / \mathrm{s})$

$\mathbf{u}_{\mathrm{i}}=$ inertial impaction velocity $(\mathrm{m} / \mathrm{s})$

$\mathrm{u}_{\mathrm{B}}=$ Brownian diffusion velocity $(\mathrm{m} / \mathrm{s})$

The deposition velocity due to gravitational settling, accounting for the bubble surface area that is perpendicular to the vertical direction, is defined as

$$
u_{g}=u_{s} \cos \theta=\frac{g \rho_{p} d_{p}^{2} C_{m}}{18 \mu} \cos \theta
$$

where

$$
\mathrm{u}_{\mathrm{s}}=\text { settling velocity }(\mathrm{m} / \mathrm{s})
$$

$\mathrm{g}=$ gravitational constant $\left(\mathrm{m} / \mathrm{s}^{2}\right)$

$\rho_{\mathrm{p}}=$ aerosol particle density $\left(\mathrm{kg} / \mathrm{m}^{3}\right)$

$\mathrm{d}_{\mathrm{p}}=$ particle diameter $(\mathrm{m})$

$\mathrm{C}_{\mathrm{m}}=$ particle mobility

$\mu=$ vapor viscosity $(\mathrm{kg} / \mathrm{m}-\mathrm{s})$

$\theta \quad=$ angle with respect to vertical (radians)

For inertial impaction, the aerosol velocity is

$$
u_{i}=\frac{9 u_{b}^{2} u_{s}}{4 R_{b} g} \sin ^{2} \theta
$$

where

$\mathrm{u}_{\mathrm{b}}=$ relative bubble rise velocity $(\mathrm{m} / \mathrm{s})$

$\mathbf{R}_{\mathrm{b}}=$ bubble radius $(\mathrm{m})$

And finally, the Brownian diffusion velocity is

$$
u_{B}=\left(\frac{D u_{b}}{R_{b}}\right)^{\frac{1}{2}}
$$

where $D$ is the particle diffusion coefficient $\left(\mathrm{m}^{2} / \mathrm{s}\right)$ in the bubble vapor.

We assumed for this model that the radius the bubbles obtain during flashing is that of 
bubbles created over a porous or heated surface by "Taylor instability" which is ${ }^{8}$

$$
R_{b} \approx\left[\frac{\sigma}{g\left(\rho_{f}-\rho_{g}\right)}\right]^{\frac{1}{2}}
$$

where

$$
\begin{aligned}
\sigma & =\text { fluid surface tension }(\mathrm{N} / \mathrm{m}) \\
\rho_{\mathrm{f}} & =\text { fluid density }\left(\mathrm{kg} / \mathrm{m}^{3}\right) \\
\rho_{\mathrm{v}} & =\text { vapor density }\left(\mathrm{kg} / \mathrm{m}^{3}\right)
\end{aligned}
$$

The bubble rise velocity of this model is the bubble velocity relative to the mixture or liquid velocity. For this velocity we have adopted formulations proposed by Peebles and Garber ${ }^{9}$ for the terminal velocity of a single gas bubble rising in a stationary liquid. These equations are

$$
\begin{array}{ll}
u_{b}=\frac{2 g R_{b}^{2}\left(\rho_{f}-\rho_{v}\right)}{9 \mu_{f}} & R e_{b}<2 \\
u_{b}=0.33 g^{0.76}\left[\frac{\rho_{f}}{\mu_{f}}\right)^{0.52} R_{b}^{1.28} & 2<R e_{b}<4.02 G_{1}^{-0.214} \\
u_{b}=1.35\left(\frac{\sigma}{\rho_{f} R_{b}}\right)^{0.50} & 4.02 G_{1}^{-0.214}<R e_{b}<3.10 G_{1}^{-0.25} \\
u_{b}=1.53\left(\frac{g \sigma}{\rho_{f}}\right)^{0.25} & 3.10 G_{1}^{-0.25}<R e_{b}
\end{array}
$$

where the bubble Reynolds number is defined as

$$
R e_{b}=\frac{2 \rho_{f} u_{b} R_{b}}{\mu_{f}}
$$

and the parameter $G_{1}$ as 


$$
G_{1}=\frac{g \mu_{f}^{4}}{\rho_{f} \sigma^{3}}
$$

By assuming that these bubbles form instantaneously, maintain a constant radius, and aerosol deposition velocities are constant over the bubble rise time, the integration of Equation 38 with respect to bubble surface area, defined as

$$
I_{B}^{S}=V_{b}^{-1} \int u d A_{b}
$$

becomes time independent. The solution for Equation 50 is somewhat complicated and will not be presented here. Those interested can find this solution in Reference 3.

We define the bubble residence time of Equation 38 as the bubble origination depth divided by the vapor velocity $\left(\mathrm{z} / \mathrm{u}_{\mathrm{v}}\right)$. This velocity is the maximum of the vapor superficial velocity and the bubble rise velocity, that is

$$
u_{v}=\max \left(\frac{\kappa_{F}}{A_{p} \rho_{v}}, u_{b}\right)
$$

where

$\kappa_{\mathrm{F}}=$ liquid mass flashing rate $(\mathrm{kg} / \mathrm{s})$.

$A_{\mathrm{p}}=$ liquid pool cross-sectional area $\left(\mathrm{m}^{2}\right)$

Recalling our discussion of Equation 38, we can now determine the aerosol mass release from a flashing pool. Assuming that this liquid flashing generates vapor bubbles uniformly throughout the pool and that the entrained aerosol mass in the flashing liquid re-suspends into the generated bubbles, then the differential aerosol mass release from the pool surface $\left(\mathrm{dm}_{\mathrm{a}}^{\mathrm{S}}\right)$ resulting from a differential aerosol mass re-suspension $\left(\mathrm{dm}_{\mathrm{a}}{ }^{\mathrm{R}}\right)$ in bubbles that develop at pool depth (z), in height (dz), is

$$
d m_{a}^{s}=d m_{a}^{R} e^{-I_{B}^{S} z / u_{v}}=\frac{m_{a}^{R}}{Z_{P}} d z e^{-I_{B}^{S} z / u_{v}}
$$

where $\mathrm{m}_{\mathrm{a}}{ }^{\mathrm{R}}$ is the total aerosol mass re-suspended over pool depth $Z_{\mathrm{p}}$. By integrating Equation 52 over the depth of the pool, the total aerosol mass release becomes

$$
m_{a}^{s}=\int_{0}^{Z_{P}} d m_{a}^{s}=\frac{m_{a}^{R} u_{v}}{I_{B}^{S} Z_{P}}\left(1-e^{-I_{B}^{s} Z_{P} / u_{v}}\right)
$$

With this result, we can now define the aerosol mass release rate $\left(\mathrm{R}_{\mathrm{a}}\right)$ in terms of the 
liquid mass flashing rate as

$$
R_{a}=\chi_{a} \kappa_{F} \frac{m_{a}^{S}}{m_{a}^{R}}=\chi_{a} \kappa_{F} S F
$$

where

$\chi_{\mathrm{a}}=$ entrained aerosol to liquid mass ratio

$\mathrm{SF}=$ aerosol scrubbing factor

Because the MELCOR aerosol module does not track the particle size distribution once the aerosols become entrained in the liquid, we assume that the aerosol mass released to the atmosphere has the minimum particle radius specified by user input.

We developed a simple test problem that illustrates the difference between our new liquid entrained aerosol re-suspension model and that of the standard MELCOR model. This test problem is a $25 \mathrm{~m}^{3}$ volume that contains $500 \mathrm{~kg}$ of water, in which resides $50 \mathrm{~kg}$ of aerosols. A constant heating rate is applied to the water to cause complete vaporization within about $10 \mathrm{~s}$. Figure 4 contains the water and entrained aerosol masses as predicted by the standard MELCOR model. As can be seen, the aerosol mass remains constant until an arbitrary liquid mass remains, after which point the aerosol mass decreases linearly with respect to the liquid mass. Figure 5 shows the difference in predicted liquid entrained aerosol mass between the standard MELCOR model and our new re-suspension model for this test problem. 


\section{COMPARISON OF AEROSOL DEPOSITION MODELS TO LACE DATA}

Over the time period of 1981 to 1988, the Electric Power Research Institute (EPRI) organized a test program, sponsored by an international consortium, that conducted a number of large-scale light water reactor (LWR) aerosol containment experiments (LACE) at the Hanford Engineering Development Laboratory (HEDL) in Richland, Washington. These tests examined the transport of aerosols typical of LWRs through pipes with high speed flow and in containment volumes during rapid de-

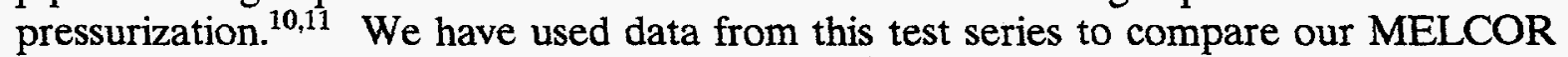
aerosol transport models against. This comparison is given in the following subsections. The first subsection describes the LACE bypass tests and tests results. The second subsection compares our model's predictions against the LACE bypass tests. The third subsection describes the LACE de-pressurization test LA5. The final subsection presents a comparison between the LACE test LA5 data and our liquid entrained aerosol re-suspension model.

\subsection{LACE Containment Bypass Tests}

Figure 6 contains a schematic of the LACE facility as it was constructed to perform the aerosol transport tests in pipes. Two test series were conducted with this facility configuration. The first test series was called the containment bypass scoping tests, designated as the CB series. The second test series was called the containment bypass tests, designated as LWR Aerosol (LA) tests LA1 and LA3. This facility had as major components an aerosol generator, a test pipe, a containment vessel, and an aerosol scrubbing/venting system. The LA tests had a different test pipe configuration than that of the $\mathrm{CB}$ tests. Both test series examined aerosol transport in pipes with high speed carrier gas flows, but the LA1 and LA3 test series considered aerosols, carrier gases, and carrier gas conditions that were more typical of containment bypass accident scenarios in LWRs.

The aerosol generator was a $5 \mathrm{~m}^{3}$ tank that was divided into a burn chamber and a mixing chamber. The burn chamber was used to vaporize sodium or cesium into an air or nitrogen carrier gas. Aluminum or manganese oxide was also produced in this chamber by the use of a plasma torch, into which the metal oxide powder was injected. These gases then entered the mixing chamber in which steam was introduced. The aerosol particles produced by this aerosol generator were $\mathrm{NaOH}, \mathrm{CsOH}, \mathrm{Al}(\mathrm{OH})_{3}$, and $\mathrm{MnO}$.

The test pipe for the CB scoping tests consisted of three pipe sections. The first and third pipe sections were $300 \mathrm{~mm}$ in diameter and approximately $3 \mathrm{~m}$ long. The center section of the test pipe was $63 \mathrm{~mm}$ in diameter and $27 \mathrm{~m}$ long. There were five $90^{\circ}$ pipe bends and three pipe reducers in this test pipe. The test pipe for the LA bypass tests eliminated the downstream $300 \mathrm{~m}$ diameter pipe section, and extended the $63 \mathrm{~mm}$ 
diameter pipe section to a length of $29 \mathrm{~m}$. This longer $63 \mathrm{~mm}$ diameter pipe had six $90^{\circ}$ pipe bends. These test pipes were wrapped with $50 \mathrm{~mm}$ of glass fiber insulation, and the first section of these pipes was electrically heated.

The containment vessel had a volume of $850 \mathrm{~m}^{3}$, surface area of $520 \mathrm{~m}^{2}$, diameter of $7.62 \mathrm{~m}$, height of $20.3 \mathrm{~m}$, wall thickness of $16.4 \mathrm{~mm}$ and was covered by $25 \mathrm{~mm}$ of glass fiber insulation. No attempt was made to maintain elevated temperatures in this volume during these tests. The resulting atmosphere temperatures were about $85^{\circ} \mathrm{C}$ for the $\mathrm{CB}$ series, and $115{ }^{\circ} \mathrm{C}$ for test LA1. The pressure during these tests was maintained at 0.1 $\mathrm{MPa}$. In the case of tests LA3A-C, this containment volume was bypassed altogether.

Test conditions measured at the inlet of the test pipes and mass retention fractions in these pipes are given in Table 1 . The carrier gas inlet conditions were maintained for 20 hours prior to conducting the one hour aerosol transport tests. The rather high carrier gas temperatures and velocities of these tests ensured that the steam in the carrier gas remained super-heated, and that the flow was highly turbulent. Of particular interest is the very dramatic difference in mass retention fraction between the $63-\mathrm{mm}$ and $300-\mathrm{mm}$ pipe sections of the CB test series. The retention fraction was less than $5 \%$ for the $63-$ $\mathrm{mm}$ pipe section, but was nearly an order of magnitude higher in the $300-\mathrm{mm}$ pipe. The LACE experimentalists offered two possible explanations for this difference. Either the aerosol material was re-suspended following deposition, or moved along the pipe as a liquid film by shear stresses induced by the high-velocity carrier gases. There is also a very noticeable difference in mass retention fraction for the $63-\mathrm{mm}$ pipe sections of the $\mathrm{CB}$ and LA tests. For example, test $\mathrm{CB} 3$ resulted in only a $1 \%$ mass retention fraction while LA1 is in excess of $98 \%$. The LACE experimentalists attributed this difference to the physical nature of the aerosol, citing surface tension, viscosity, and melting point as important parameters effecting adhesion and re-suspension.

The reason for suspecting the formation of a film in these experiments is that $\mathrm{NaOH}$ and $\mathrm{CsOH}$ are hygroscopic materials, which means that these aerosols will rapidly absorb steam from the carrier gas. It is these particles that could agglomerate and form a film on the pipe surface. However, aerosol transport by shear stress induced film motion has two problems with regards to the CB test series. The first problem is that test $\mathrm{CB} 3 \mathrm{had}$ no hygroscopic aerosols to form a film, therefore film transport could not explain the small retention fraction for this test. The second problem is that even for the largest retention fraction, which is $5 \%$ for test $\mathrm{CB} 2$, the film height is only about $17 \mu \mathrm{m}$. This compares to an expected surface roughness height for this test pipe of $50 \mu \mathrm{m}$. As a result, the film would be below the viscous sublayer and would not experience the shear stress forces produced by the carrier gas.

Aerosol re-suspension was also given as a possible explanation for the low retention factors of the $\mathrm{CB}$ test series. Hall ${ }^{12}$ has measured the mean lifting forces on a captive sphere near to a surface in fully developed turbulent boundary layer. He demonstrated 
Table 1. Aerosol and Thermal-Hydraulic Conditions at Inlet to Test Pipe

\begin{tabular}{|c|c|c|c|c|c|c|c|c|c|}
\hline \multirow[b]{2}{*}{ Test } & \multirow[b]{2}{*}{ Aerosol } & \multirow{2}{*}{$\begin{array}{c}\mathrm{NaOH} \text { or } \\
\mathrm{CsOH} \\
\text { Mass Fraction }\end{array}$} & \multirow[b]{2}{*}{$\begin{array}{c}\text { Carrier } \\
\text { Gas }\end{array}$} & \multirow{2}{*}{$\begin{array}{c}\text { Gas } \\
\text { Velocity } \\
(\mathrm{m} / \mathrm{s})\end{array}$} & \multirow[b]{2}{*}{$\begin{array}{c}\text { Temp. } \\
\left({ }^{\circ} \mathrm{C}\right)\end{array}$} & \multirow{2}{*}{$\begin{array}{r}\text { Aerosol } \\
\text { Source } \\
\text { Rate }(\mathrm{g} / \mathrm{s})\end{array}$} & \multirow{2}{*}{$\begin{array}{l}\text { Aerosol } \\
\text { Size } \\
\text { AMMD } \\
(\mu \mathrm{m})\end{array}$} & \multicolumn{2}{|c|}{$\begin{array}{l}\text { Mass Retention } \\
\text { Fractions of Test Pipes }\end{array}$} \\
\hline & & & & & & & & 63-mm & $300-\mathrm{mm}$ \\
\hline CB1 & $\mathrm{NaOH}$ & 1.00 & Air-steam & 100 & 186 & 3.0 & 3.9 & 0.03 & 0.55 \\
\hline $\mathrm{CB} 2$ & $\begin{array}{c}\mathrm{NaOH} \\
\mathrm{Al}(\mathrm{OH})_{3}\end{array}$ & 0.67 & Air-steam & 91 & 111 & 0.9 & 3.1 & 0.05 & 0.48 \\
\hline CB3 & $\mathrm{Al}(\mathrm{OH})_{3}$ & 0.00 & Air-steam & 97 & 160 & 2.0 & 4.3 & 0.01 & 0.14 \\
\hline LA1 & $\begin{array}{l}\mathrm{CsOH} \\
\mathrm{MnO}\end{array}$ & 0.42 & Air-steam & 96 & 247 & 1.1 & 1.6 & $>0.98$ & NA \\
\hline LA3A & $\begin{array}{l}\mathrm{CsOH} \\
\mathrm{MnO}\end{array}$ & 0.18 & $\mathrm{~N}_{2}$-steam & 75 & 298 & 0.6 & 1.4 & $\begin{array}{c}\mathrm{CsOH}:>0.7 \\
\mathrm{MnO}: 0.7\end{array}$ & NA \\
\hline LA3B & $\begin{array}{l}\mathrm{CsOH} \\
\mathrm{MnO}\end{array}$ & 0.12 & $\mathrm{~N}_{2}$-steam & 24 & 303 & 0.9 & 2.4 & $\begin{array}{l}\mathrm{CsOH}:>0.4 \\
\mathrm{MnO}:>0.7\end{array}$ & NA \\
\hline LA3C & $\begin{array}{l}\mathrm{CsOH} \\
\mathrm{MnO}\end{array}$ & 0.38 & $\mathrm{~N}_{2}$-steam & 23 & 300 & 0.9 & 1.9 & $\begin{array}{l}\mathrm{CsOH}:>0.7 \\
\mathrm{MnO}:>0.7\end{array}$ & NA \\
\hline
\end{tabular}


that a universal relationship exits between the normalized sphere radius $\left(\mathrm{ru}_{\tau} / \nu_{\mathrm{f}}\right)$ and the normalized average lift force $\left(\left\langle\mathrm{F}_{\mathrm{L}}\right\rangle / \nu_{\mathrm{f}} \rho_{t}\right)$. An empirical relationship derived by Hall for his data is

$$
\frac{<F_{L}>}{\nu_{f}^{2} \rho_{f}}=20.9\left(\frac{r u_{\tau}}{\nu_{f}}\right)^{2.31} \quad\left(1.8>r u_{\tau} / \nu_{f}>70\right)
$$

Using this relationship, the lift force in the $63-\mathrm{mm}$ pipe of test $\mathrm{CB} 3$ would be $6 \times 10^{-9} \mathrm{~N}$, which compares to a Van der Waals surface adhesive force that could vary from $4 \times 10^{-8}$ to $2 \times 10^{-7} \mathrm{~N}$ depending on the assumed surface energy density. Given these numbers, it is difficult to see how re-suspension could occur.

Surface adhesion does play an important role in aerosol deposition. This can be seen from the measured differences between the CB and LA series. In Appendix A we present the reason the LA test series surface adhesive properties were larger than those of the CB tests series. One thing that is certain from the LA test series is that aerosol deposition velocities for high speed flows in pipes are large. There is no reason to suspect that was not the case for the $\mathrm{CB}$ test series as well.

\subsection{MELCOR Results for LACE Containment Bypass Tests}

Figure 7 contains the predicted mass retention fractions for the $63-\mathrm{mm}$ diameter pipe of test CB3. We have examined this particular test for two reasons. First, this test is more representative of conditions that would exist during ITER accident scenarios. Second, test CB3 does not introduce hygroscopic aerosols, thereby eliminating the possible influence this material would have on surface adhesion forces. Three curves appear in Figure 7. These curves show the effect of varying the Van der Waals surface energy density, for a fixed surface reduction factor of 0.1 . Our deposition models give $2.75 \%$ for a Van der Waals surface energy density of $0.04 \mathrm{~J} / \mathrm{m}^{2}$. This value is close to the measured retention fraction of $1 \%$ for test $\mathrm{CB} 3$.

Our model predicted the order of significance for the various deposition mechanisms was turbulence, gravitational settling, and inertial impact deposition, respectively. While a surface energy density of $0.04 \mathrm{~J} / \mathrm{m}^{2}$ was at the lower end of the range stated by Reek, it is in line with the effect demonstrated by Benson ${ }^{13}$ that the first layer of deposition is more tightly bound to a surface than subsequent layers, that is the surface energy density decreases with increasing numbers of deposition layers. A mass retention fraction of $1 \%$ results in a deposition layer height of about $5.6 \mu \mathrm{m}$, which is only slightly larger than the particle diameter for this test (e.g. $4.3 \mu \mathrm{m})$. According to the MELCOR models, a $1 \%$ mass retention fraction is less than the deposition fraction that would occur from gravity alone. However, the MELCOR aerosol deposition model assumes that various deposition mechanisms occur independently. When we apply the turbulent deposition adhesion factor to gravitational settling, the predicted retention fraction for CB3 drops to 
$1.2 \%$. Since this is more representative of the data, this assumption has become part of our new MELCOR aerosol deposition model.

The mass retention fraction for the 300-mm diameter pipe of test CB3 was $14 \%$.

However, our model for Van der Waals surface forces alone results in only about $0.6 \%$ mass retention fraction for this section of the test pipe. This predicted deposition was primarily due to inertial deposition from the single bend in this pipe section, because turbulent deposition was predicted to be negligible even though the Reynolds number indicated turbulent flow $\left(\operatorname{Re} \approx 8 \times 10^{4}\right)$.

In searching for an explanation for this under prediction, we looked for the possibility of steam condensation in this test pipe section (recall that the upstream 300-mm pipe section was electrically heated). Figure 8 contains predicted pipe temperatures for test $\mathrm{CB}$, assuming an initial temperature of $433 \mathrm{~K}\left(160^{\circ} \mathrm{C}\right)$ and an artificially low material density for the pipe wall and glass fiber insulation. The low density assumption was adopted to allow our model to reach thermal equilibrium within the time-scale of the aerosol deposition portion of the experiment. In the actual experiment, a precondition phase occurred where the pipes were allowed 20 hours to obtain thermal equilibrium. As can be seen, the 300 -mm diameter pipe surface temperature drops to $374 \mathrm{~K}\left(101{ }^{\circ} \mathrm{C}\right)$ for this test. This indicates the possibility of steam condensation on this surface. If we include the adhesive properties of a water film on this pipe surface, the mass retention factor increases to $6 \%$. This is still a factor of two or more below the measured retention fraction of test $\mathrm{CB} 3$, and a factor of eight below that for tests $\mathrm{CB} 1$ and $\mathrm{CB} 2$. This means that either our turbulence and inertial deposition models under predict the deposition velocities for these tests, or that there is an additional deposition mechanism that we have yet to account for. From the piping schematic of these tests (note Figure 6 ), it can be seen that this pipe section has an inlet area expansion and an outlet area contraction. Both of these area changes could produce inertial deposition from either flow directional changes or eddy currents. Since we do not have a model for these deposition mechanisms, and since the reported test results do not give an indication of where the deposition occurs, we did not pursue this matter any further. However, this does point up the need for additional experiments.

As a final comparison, we have examined test LA1. Figure 9 contains the predicted retention fraction for the surface tension and viscosity of the deposited material as presented in Appendix A. The predicted retention factor is $98.4 \%$, which is in agreement with the reported results from test LA1. The dominate surface adhesive force in this prediction was the viscous drag experienced by an aerosol particle as it passes through the film.

\subsection{LACE Containment De-pressurization Tests}

The containment de-pressurization LACE tests LA5 and LA6 used the same aerosol generator and containment vessel as the containment bypass tests described in Section 
5.1. A schematic of the LA5 and LA6 test configuration is given in Figure 10. For these de-pressurization tests, the aerosol generator and containment vessel were attached by an five meter long $200 \mathrm{~mm}$ diameter aerosol delivery pipe. An internal tank was installed in the containment vessel for these tests. This tank contained a saturated water pool that flashed to vapor as the containment volume de-pressurized. The depressurization of the containment vessel was accomplished by adding a $12.7 \mathrm{~m}$ long, $444 \mathrm{~mm}$ diameter discharge pipe to the containment vessel. In this discharge pipe was one $90^{\circ}$ pipe bend and a fast-opening butterfly valve (opening time $\sim 4 \mathrm{~s}$ ). Prior to the de-pressurization phase of these experiments, the containment vessel and flashing pool were heated to thermal equilibrium and pressurized by a steam delivery system.

For test $\mathrm{LA6}, \mathrm{CsOH}$ and $\mathrm{MnO}$ aerosols were introduced into the vapor volume of the containment vessel by the aerosol generator. These aerosols were not introduced in test LA5. The water in the internal tank contained $\mathrm{Li}_{2} \mathrm{SO}_{4}$ and $\mathrm{ZnO}$ aerosols. The $\mathrm{Li}_{2} \mathrm{SO}_{4}$ aerosol is a water soluble aerosol, and $\mathrm{ZnO}$ is water insoluble. Twenty three $\mathrm{kg}$ of $\mathrm{ZnO}$ were added to this tank, however less than $0.5 \%$ of this material remained suspended in the liquid pool. Since it is the insoluble aerosol that most closely represents corrosion products in the ITER HTS, we have selected test LA5 to benchmark our liquid entrained aerosol re-suspension model.

We did not model the pre-test conditioning phase of the LA5 experiment. Instead we used measured parameters of containment vessel pressure, gas temperature and wall temperature, and internal tank water temperature, water mass and $\mathrm{ZnO}$ concentrations prior to de-pressurization as initial conditions for our benchmark analysis. The initial containment vessel pressure, gas temperature and wall temperature where $440 \mathrm{kPa}$, $125^{\circ} \mathrm{C}$, and $121^{\circ} \mathrm{C}$, respectively. The initial internal tank water temperature, water mass and $\mathrm{ZnO}$ concentration were $135{ }^{\circ} \mathrm{C}, 5,130 \mathrm{~kg}$ and $13.5 \mathrm{mg} / \mathrm{L}$, respectively. These parameters represent averages of multiple measurements for test LA5.

\subsection{MELCOR Results for LACE Containment De-pressurization Tests}

Figures 11 and 12 contain a comparison between MELCOR predictions and LA5 test measurements of containment vessel pressure and gas temperature. As can be seen, very good agreement was obtained for vessel pressure and only a slight variance $(\sim 6 \%$ at 60 s) occurs for vessel gas temperature. During this de-pressurization, MELCOR predicts that $\sim 20 \%$ of the liquid in the internal tank vaporizes, leaving the remainder in the internal tank. However, post-test examinations of the LA5 internal tank pool depth suggests that only $40 \%$ of the pool remained in the tank. This means that an additional $40 \%$ of the liquid was expelled by pool expansion (i.e. pool swell caused by vapor generation). We could have more accurately modeled this pool expulsion by sub-dividing this pool into a number of axial volumes. But due to the accuracy of the $\mathrm{ZnO}$ concentration measurements for this test we felt this level of modeling detail was not warranted. 
Figure 13 contains the predicted and measured $\mathrm{ZnO}$ concentration in the atmosphere of the containment vessel following vessel de-pressurization. There is good agreement regarding the predicted magnitude of the $\mathrm{ZnO}$ released from the pool as the pool flashes during containment vessel de-pressurization. There was approximately $15 \mathrm{~g}$ of $\mathrm{ZnO}$ associated with the predicted liquid inventory that flashes. By taking the $\mathrm{ZnO}$ concentration of $0.5 \mathrm{mg} / \mathrm{m}^{3}$ as an accurate measurement of the re-suspended aerosol mass, one can arrive at only $0.4 \mathrm{~g}$ being re-suspended during this test, which implies an aerosol scrubbing factor of $2.8 \%$. There appears to be rapid drop in measured $\mathrm{ZnO}$ concentration, followed by a slower long term decay in $\mathrm{ZnO}$ concentration that our model only shows fair agreement with. This disagreement could be caused by aerosol scrubbing from the atmosphere by liquid drops, which in MELCOR is a user specified quantity.

We should mention in concluding this section that the agreement our model achieved with the $\mathrm{ZnO}$ measurements of test LA5 is somewhat fortuitous, and should not be relied upon too heavily because the LACE experimentalists did not give much credence to their $\mathrm{ZnO}$ concentration measurements. They cited problems with a high $\mathrm{Zn}$ background concentration, for test LA6 in particular, that cast doubts on their measurements. However, we present this comparison here to illustrate that our liquid entrained aerosol re-suspension model is within reason given the data presently available. We strongly urge that experiments like LA5 be conducted with ITER-relevant materials and geometries to improve the confidence level of our re-suspension model. 


\section{CONCLUSIONS}

In this EDF we presented the details of recent modifications we have made to the MELCOR code aerosol transport model. These modifications address the issues of predicting aerosol deposition in gases other than air, turbulence and inertial aerosol deposition for high speed flows in ducts, and re-suspension of aerosols that are entrained in ITER coolants when these coolants flash. Our intent was to improve the accuracy of MELCOR's aerosol model for ITER safety analyses, such as LOCAs into the ITER vacuum vessel that re-suspend eroded first wall and divertor material, and corrosion products in ITER's HTS coolant.

We have benchmarked these modifications against data from the LACE experiments and found excellent agreement. For high speed flows in pipes with $90^{\circ}$ pipe bends, our model predicts that $\sim 3 \%$ of the aerosol mass entering the LACE CB3 test pipe remains on the pipe walls if a Van der Waals surface energy density of $0.04 \mathrm{~J} / \mathrm{m}^{2}$ is assumed. This compares with a measured value of $1 \%$. When we extend our surface adhesion model to include gravitational settling, the predicted pipe aerosol mass retention fraction drops to $1.2 \%$. If the deposited aerosol films are highly viscous, as was the case for LACE test LA1, our model predicts that $98.4 \%$ of the aerosol mass entering the LACE test pipe will remain on the pipe wall. The measured aerosol mass retention fraction was reported as greater that $98 \%$. We have found good agreement between our model and the data from the LACE containment de-pressurization test LA5. MELCOR predicted pressures and temperatures that are within $6 \%$ of those measured by this test. In addition, the peak concentration of aerosols re-suspended as a result of pool flashing was predicted to reach $0.58 \mathrm{mg} / \mathrm{m}^{3}$ compared to a measured value of $0.48 \mathrm{mg} / \mathrm{m}^{3}$.

However, even given the success of this benchmarking exercise, there are still some unanswered issues with respect to our modified MELCOR aerosol transport module. These issues primarily center around aerosol chemical characteristics and carrier gas conditions of the LACE experiments being different than those expected in ITER, and the accuracy of some the LACE measurements. As a consequence, we suggest that additional aerosol transport tests be performed to obtain data more characteristic of ITER accident conditions, and to improve the confidence level we have in our aerosol transport module. 


\section{REFERENCES}

1. R. M. Summers, R. K. Cole, Jr., E. A. Boucheron, M. K. Carmel, S. E. Dingman, J. E. Kelly, MELCOR 1.8.0: A Computer Code for Nuclear Reactor Severe Accident Source Term and Risk Assessment Analyses, NUREG/CR-5531 and SAND90-0364, January 1991.

2. D. L. Hagrman, et al., Assessment of CONTAIN and MELCOR for Performing LOCA and LOVA Analyses in ITER, EGG-FSP-11386, September 1994.

3. E. A. Boucheron, et al., "Radionuclide (RN) Package Reference Manual," SNLA MELCOR Reference Manual, February 25, 1993.

4. $\quad$ N. B. Wood, "A Simple Method for the Calculation of Turbulent Deposition to Smooth and Rough Surfaces," Journal of Aerosol Science, 12, 2, 1981, pp. 275-290.

5. M. B. Ranade, "Adhesion and Removal of Fine Particles on Surfaces," Aerosol Science and Technology 7, pp. 161-176, 1987.

6. M. W. Reeks, J. Reed, and D. Hall, "On the Resuspension of Small Particles by a Turbulent Flow," Journal of Physics D: Applied Physics, 21, 1987, pg 49.

7. J. R. Welty, C. E. Wicks, and R. E. Wilson, Fundamentals of Momentum, Heat and Mass Transfer, New York, John Wiley \& Sons, Inc, 1969, p. 185.

8. G. B. Wallis, One-dimensional Two-phase Flow, New York, McGraw-Hill Book Company, 1969, p. 246.

9. F. N. Peebles, and H. J. Garber, Chemical Engineering Progress, 49, pp.88-97, 1953.

10. F. J. Rahn, The PWR Aerosol Containment Experiments (LACE) Project Summary Report, EPRI, LACE TR-012/NP-6094-D, January 15, 1989.

11. D.R. Dickson, D.C. Mecham, and D.C. Slaughterbeck, Final Report of Experimental Results of LACE Tests LA5 and LA6 - Rapid Containment De-pressurization, Westinghouse Hanford Company, LACE TR-026, September 1988.

12. D. Hall, "Measurements of the Mean Force on a Particle Near a Boundary in Turbulent Flow," Journal of Fluid Mechanics, 187, 1998, pp. 451-466.

13. C. G. Benson and B. R. Bowsher, Physical Resuspension and Revaporisation Phenomena in Control Rod Aerosols, AEEW-R2427, December 1988. 


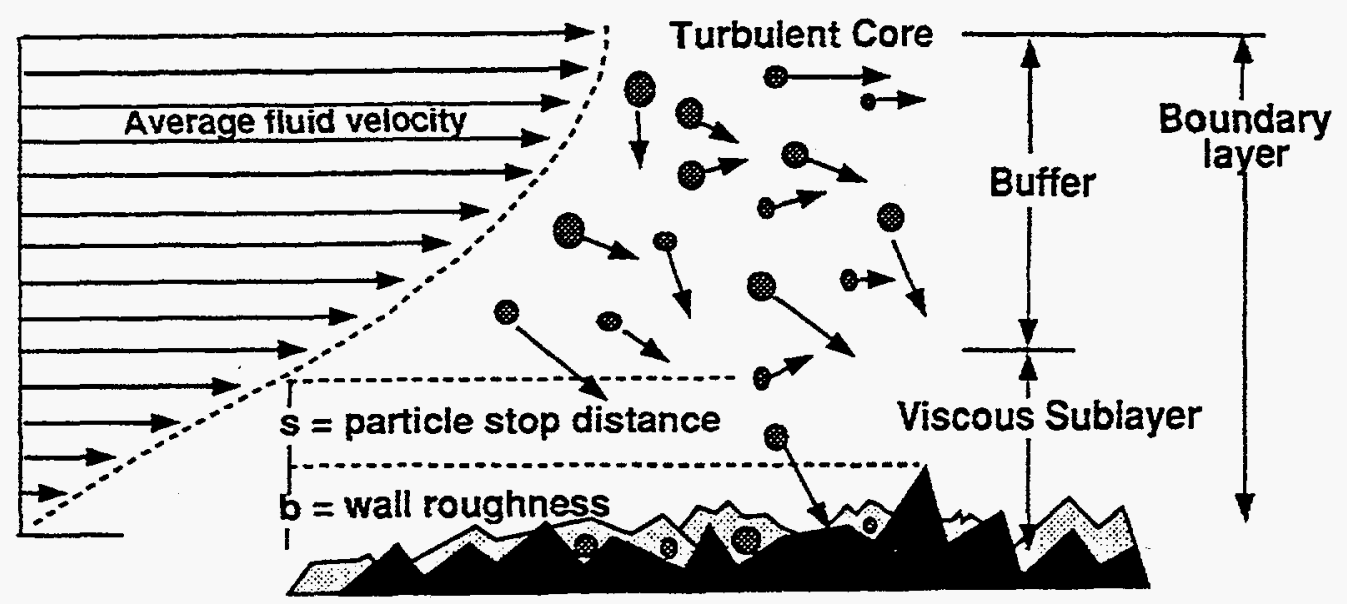

Turbulent Deposition

(1a)

Particles with too much inertia cannot follow fluid around bend and impact pipe walls

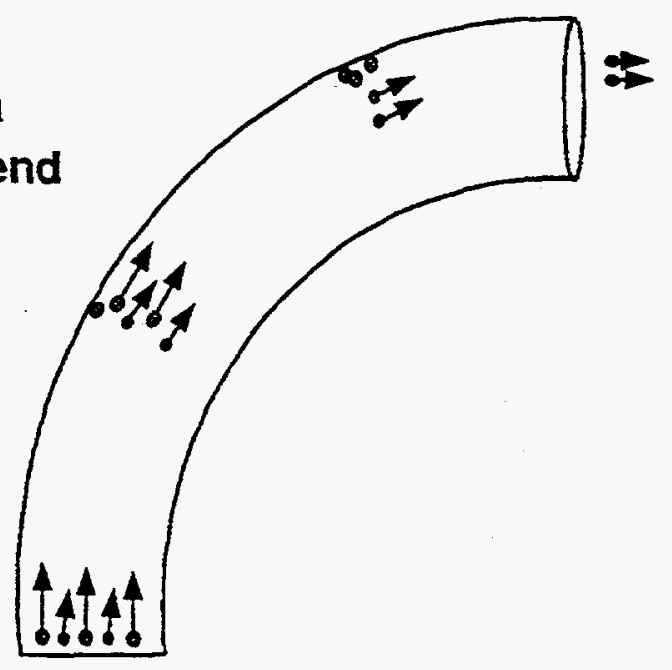

Inertial Impact Deposition

(1b)

Figure 1. Schematic diagram of turbulence and inertial impact aerosol deposition mechanisms. 


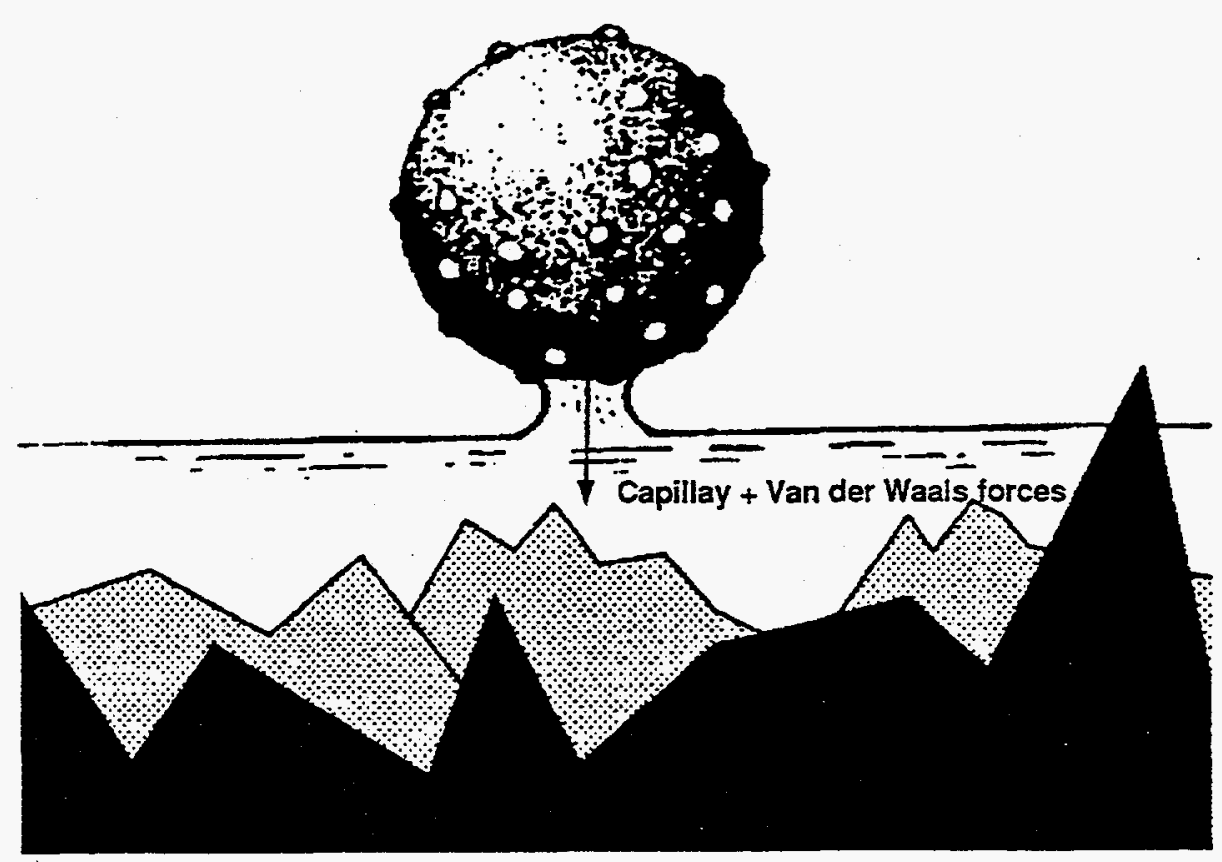

Figure 2. Illustration of aerosol particle impact on a surface with a liquid film.

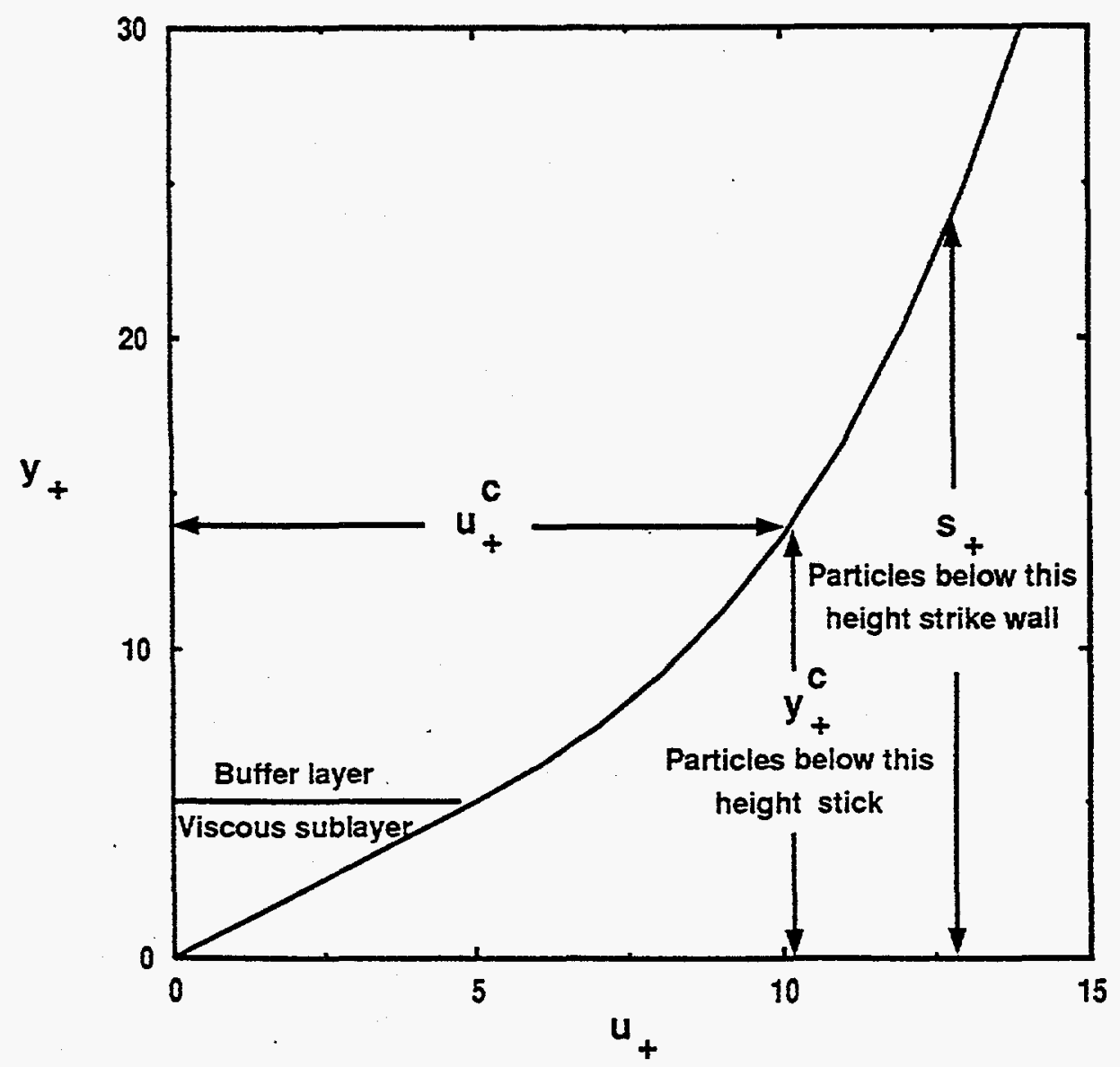

Figure 3. Universal velocity profile for viscous sublayer and buffer layer of internal turbulent flow. 


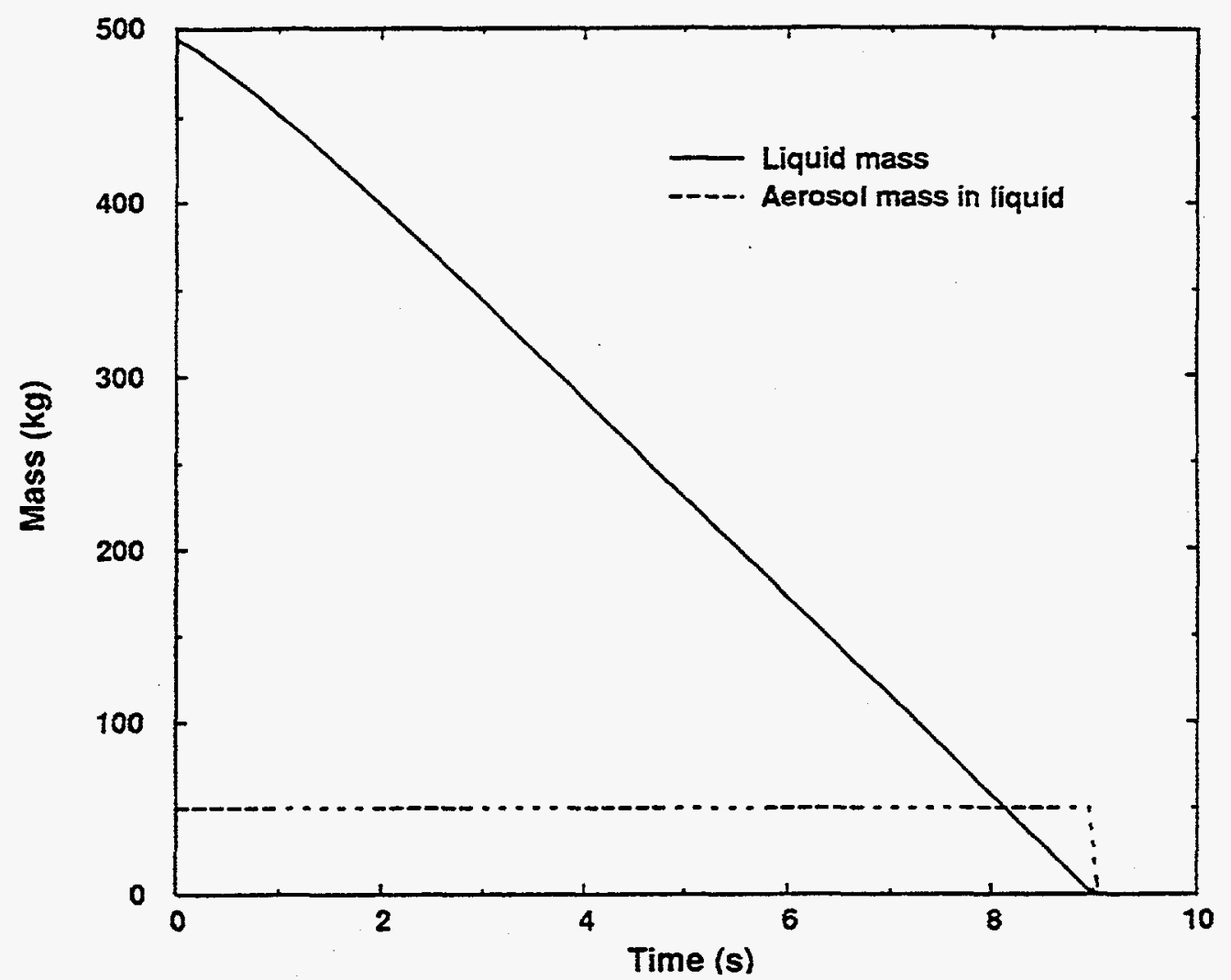

Figure 4. Liquid and entrained aerosol masses for simple test problem using the standard MELCOR entrained aerosol re-suspension model.

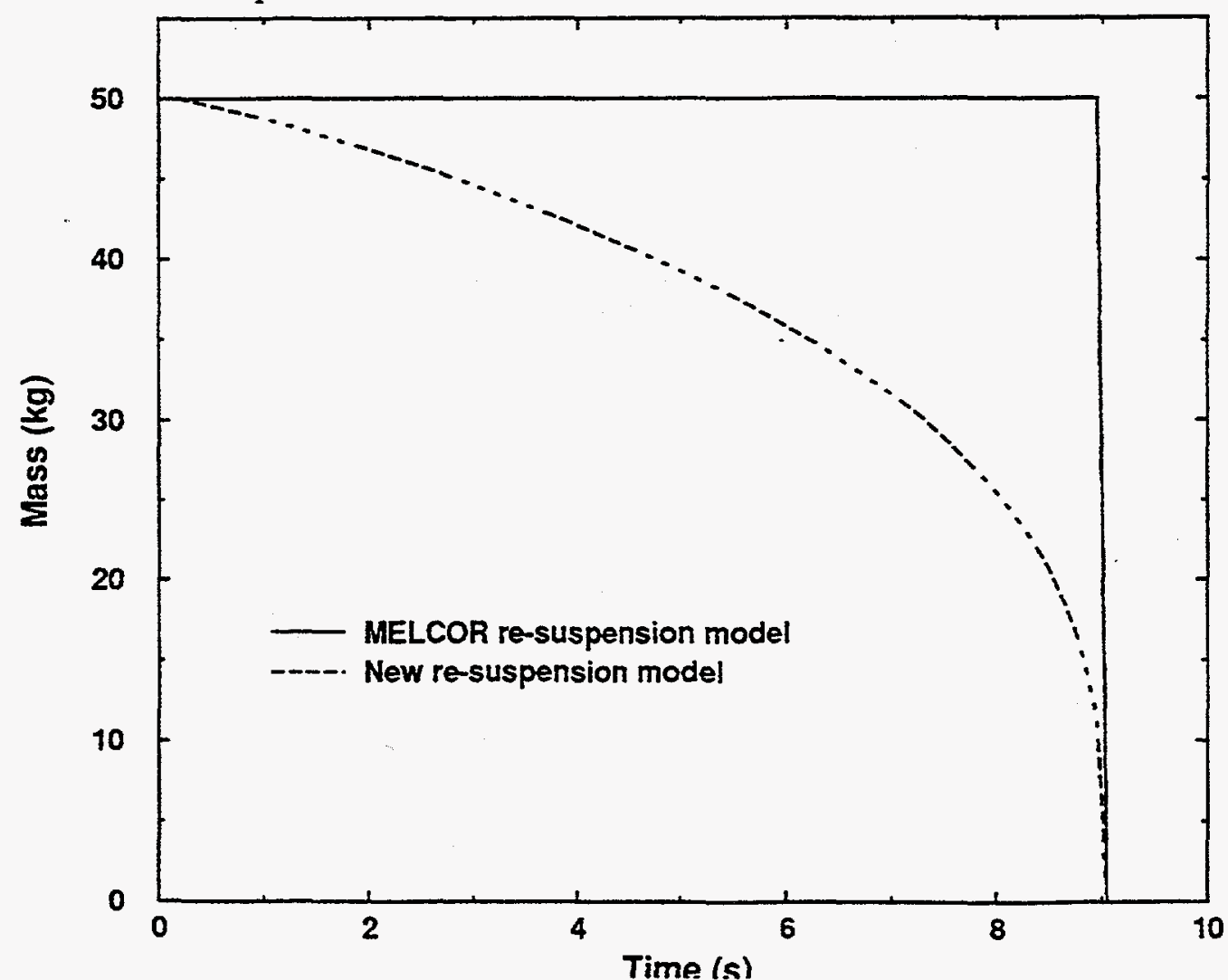

Figure 5. Comparison between entrained aerosol re-suspension models for the simple test problem. 


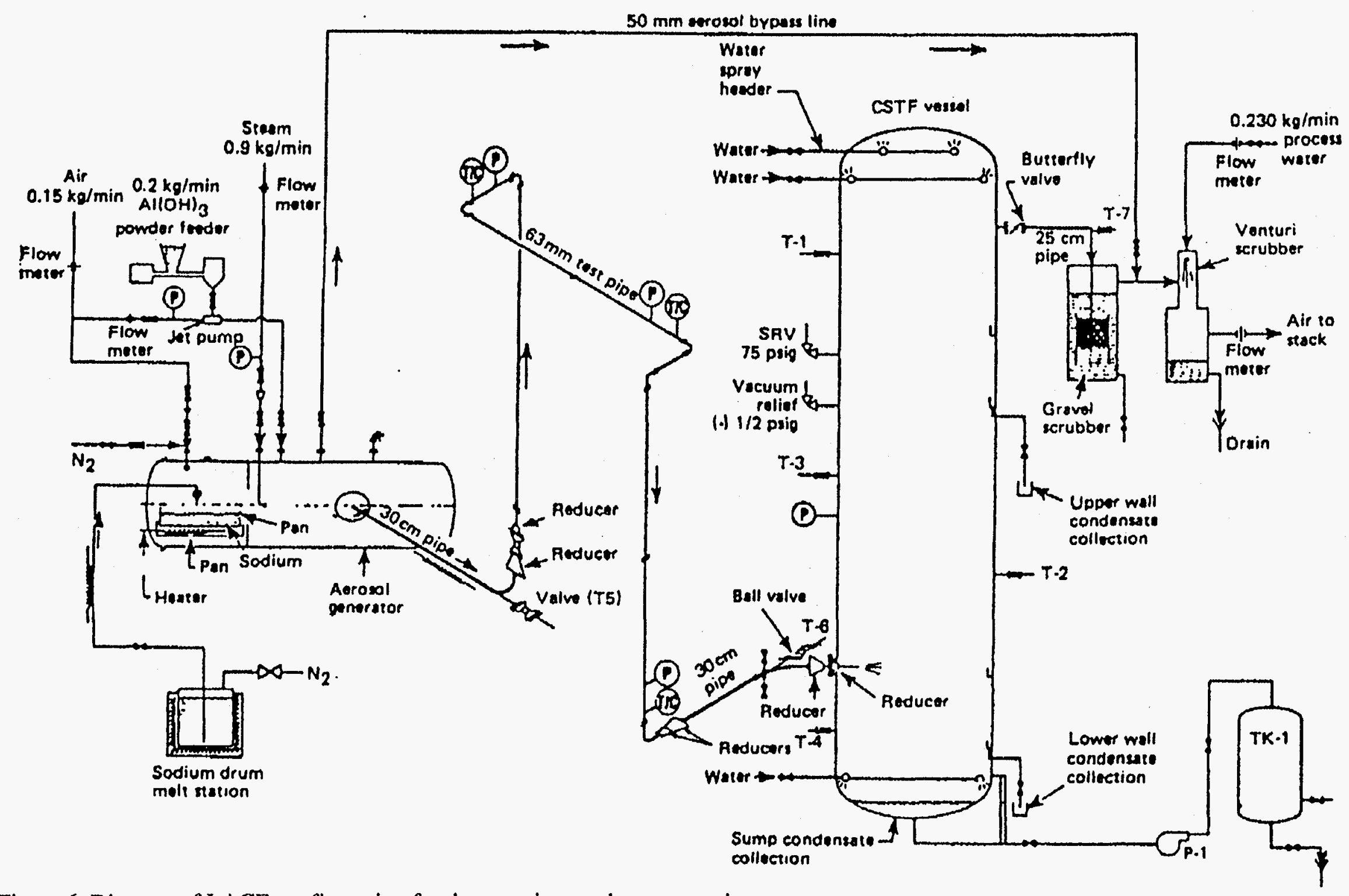

Figure 6. Diagram of LACE configuration for the containment bypass scoping tests. 


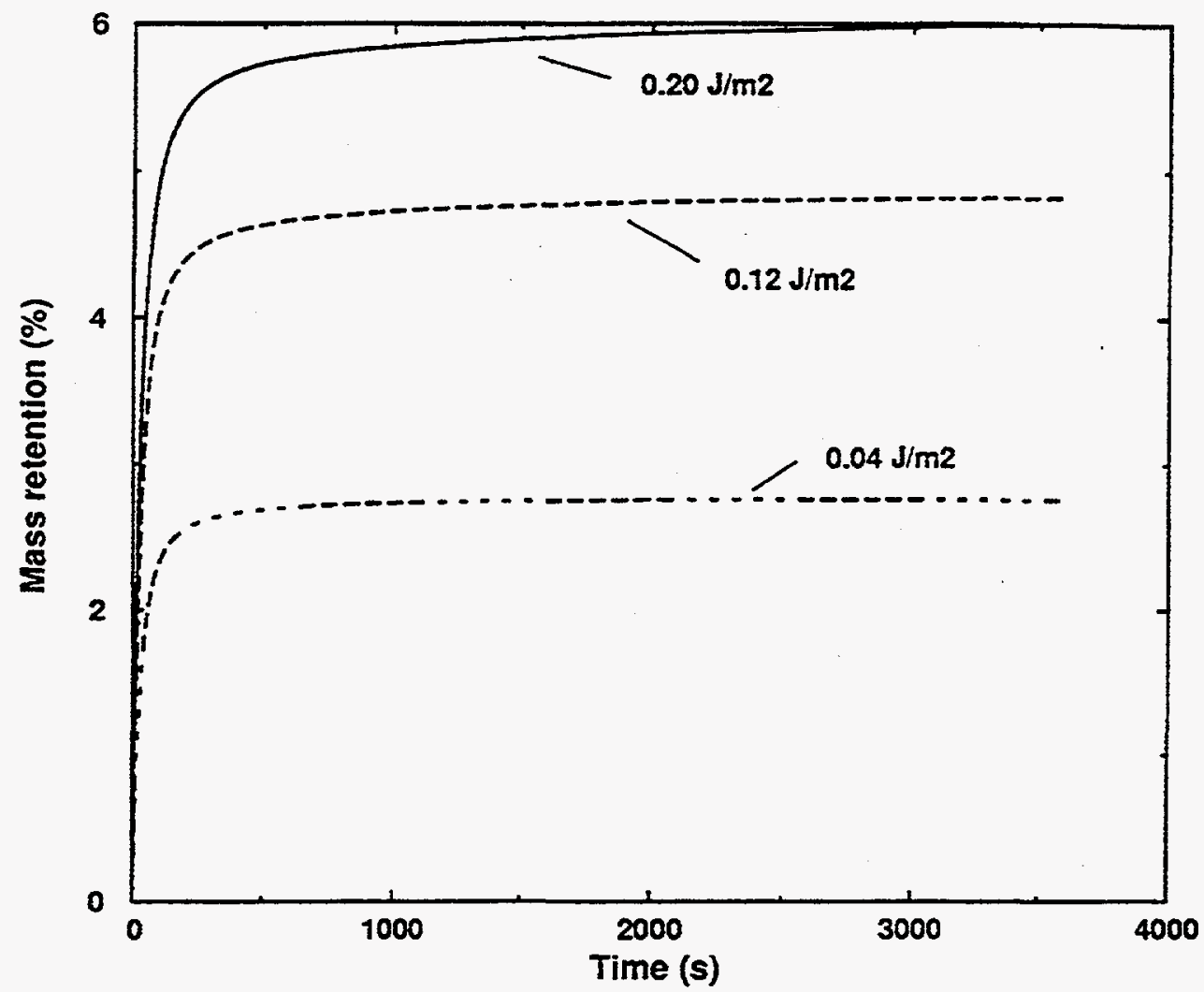

Figure 7. Mass retention fraction in 63-mm diameter pipe for containment bypass scoping test CB3 for different $V$ an der Waals surface energy densities.

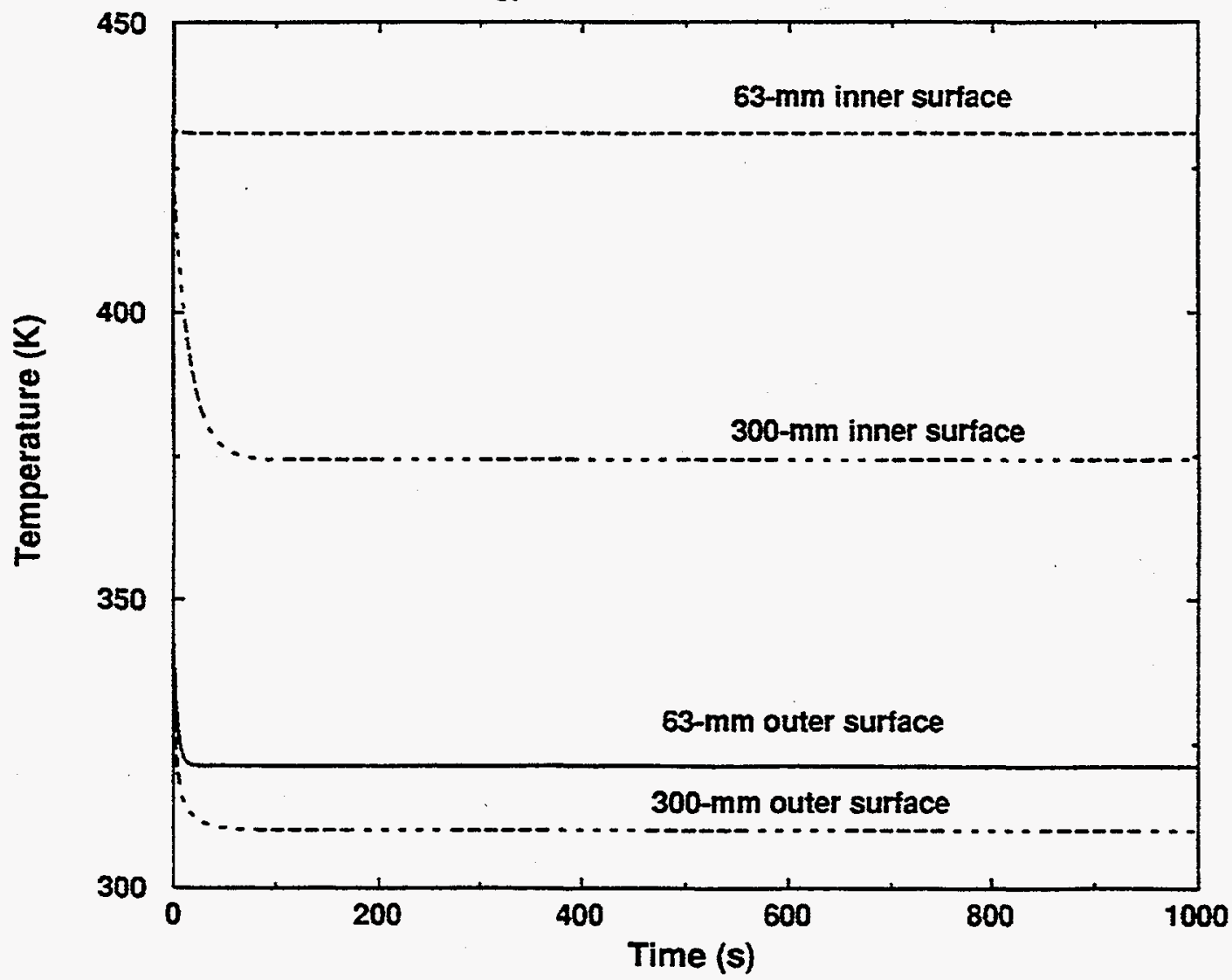

Figure 8. Test pipe temperatures for containment bypass scoping test CB3. 


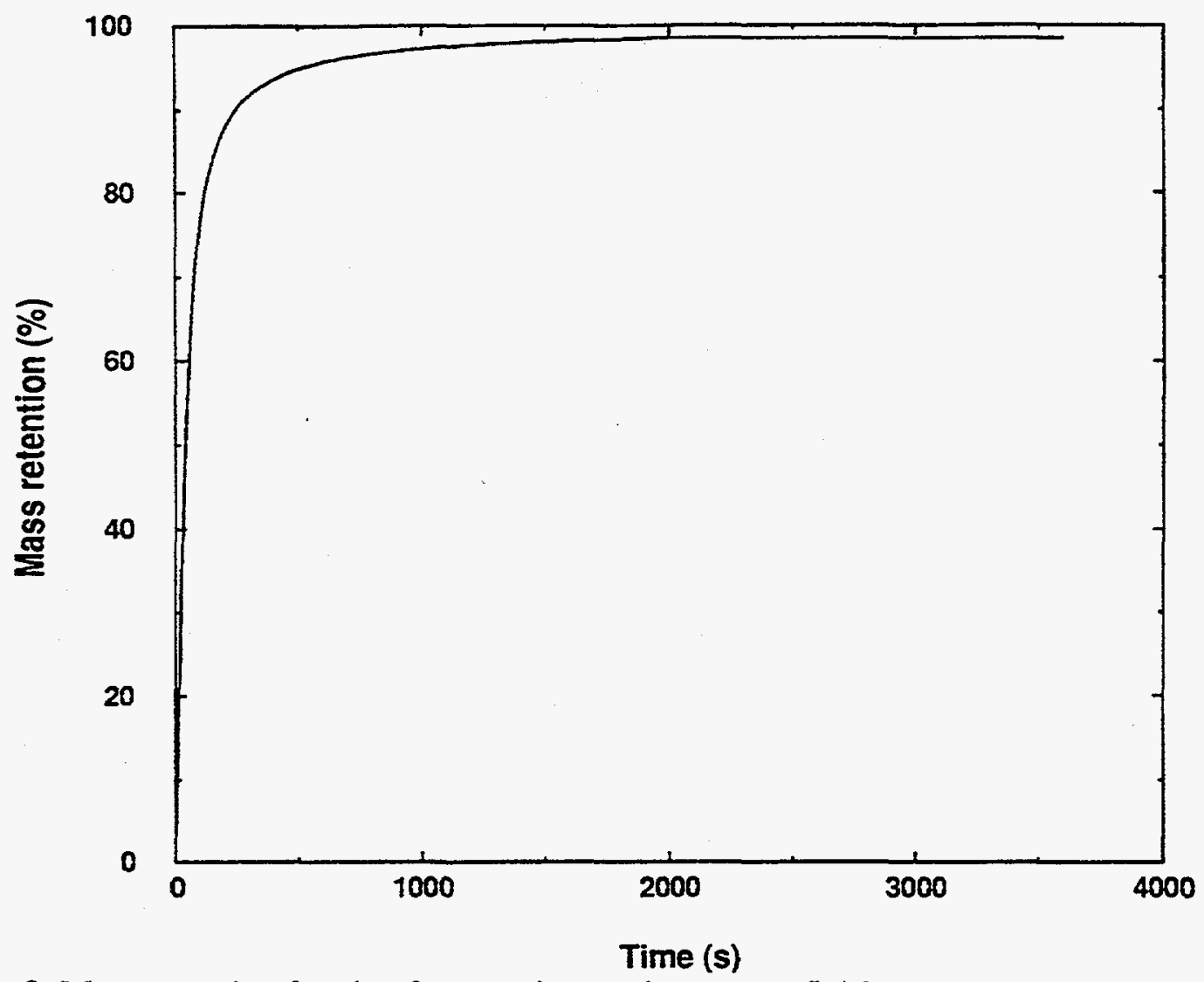

Figure 9. Mass retention fraction for containment bypass test LA1. 

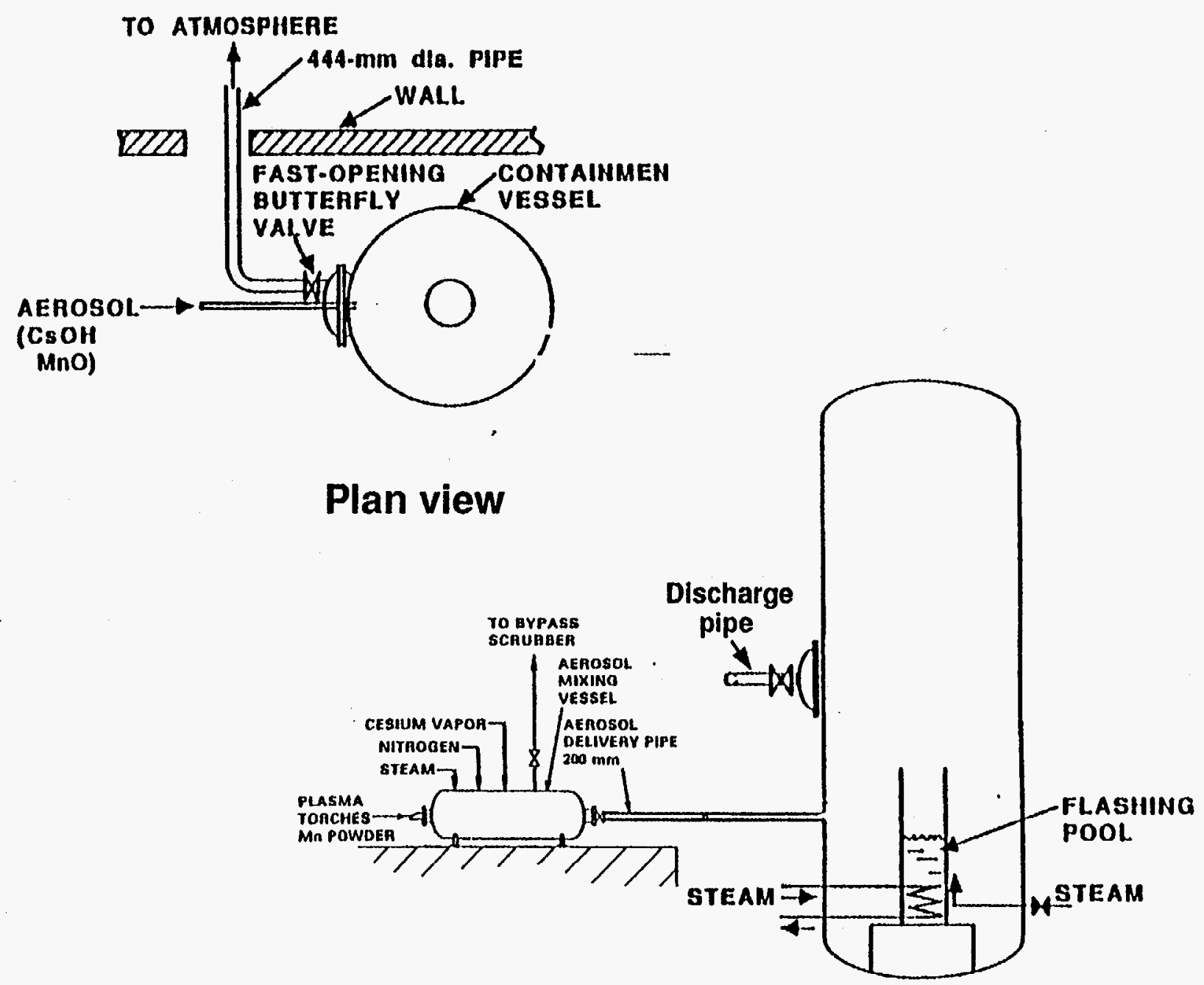

\section{Elevation view}

Figure 10. LACE test configuration for de-pressurization tests LA5 and LA6. 


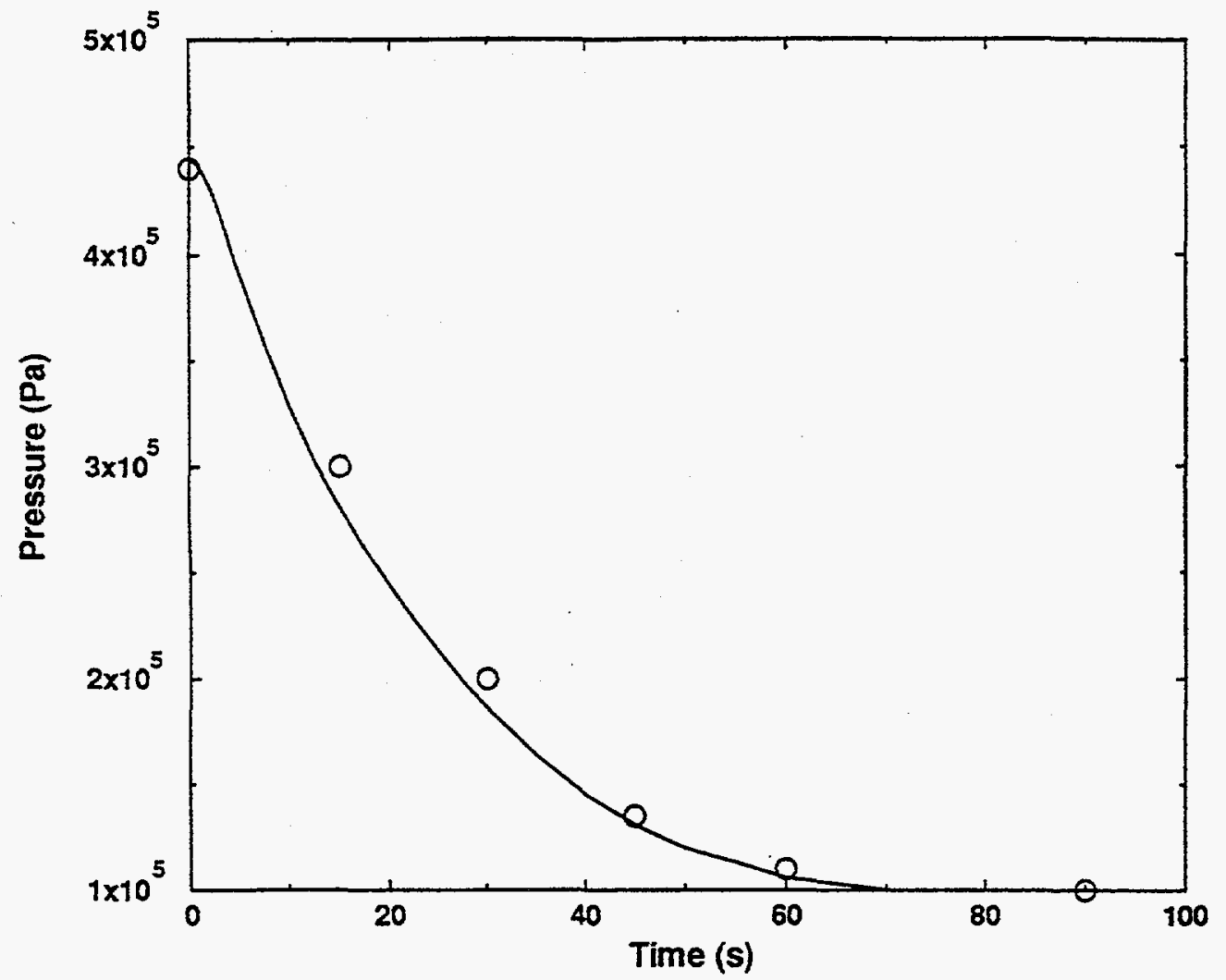

Figure 11. MELCOR predicted and measured containment vessel pressure for LACE test LA5.

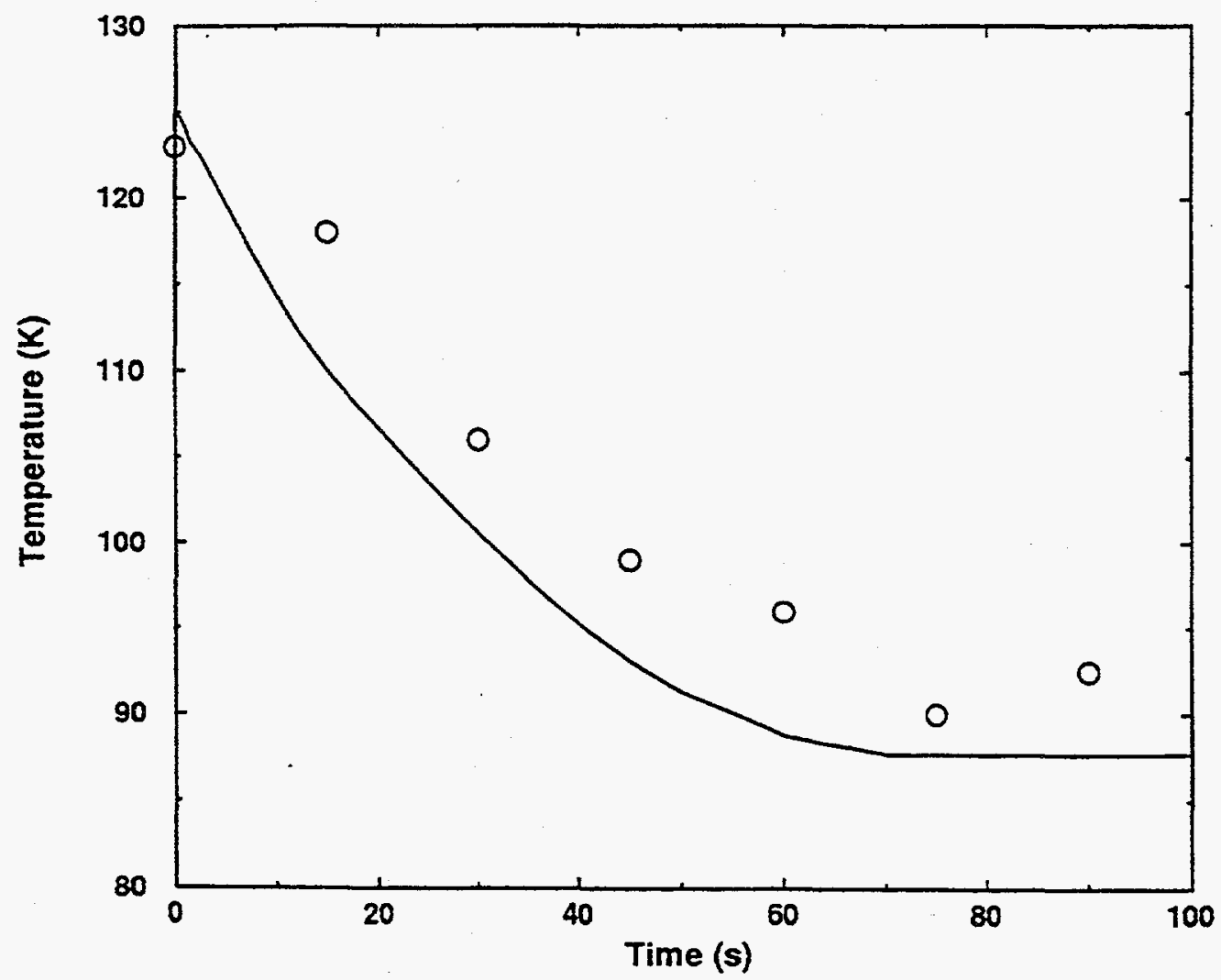

Figure 12. MELCOR predicted and measured containment vessel temperature for LACE test LA5. 


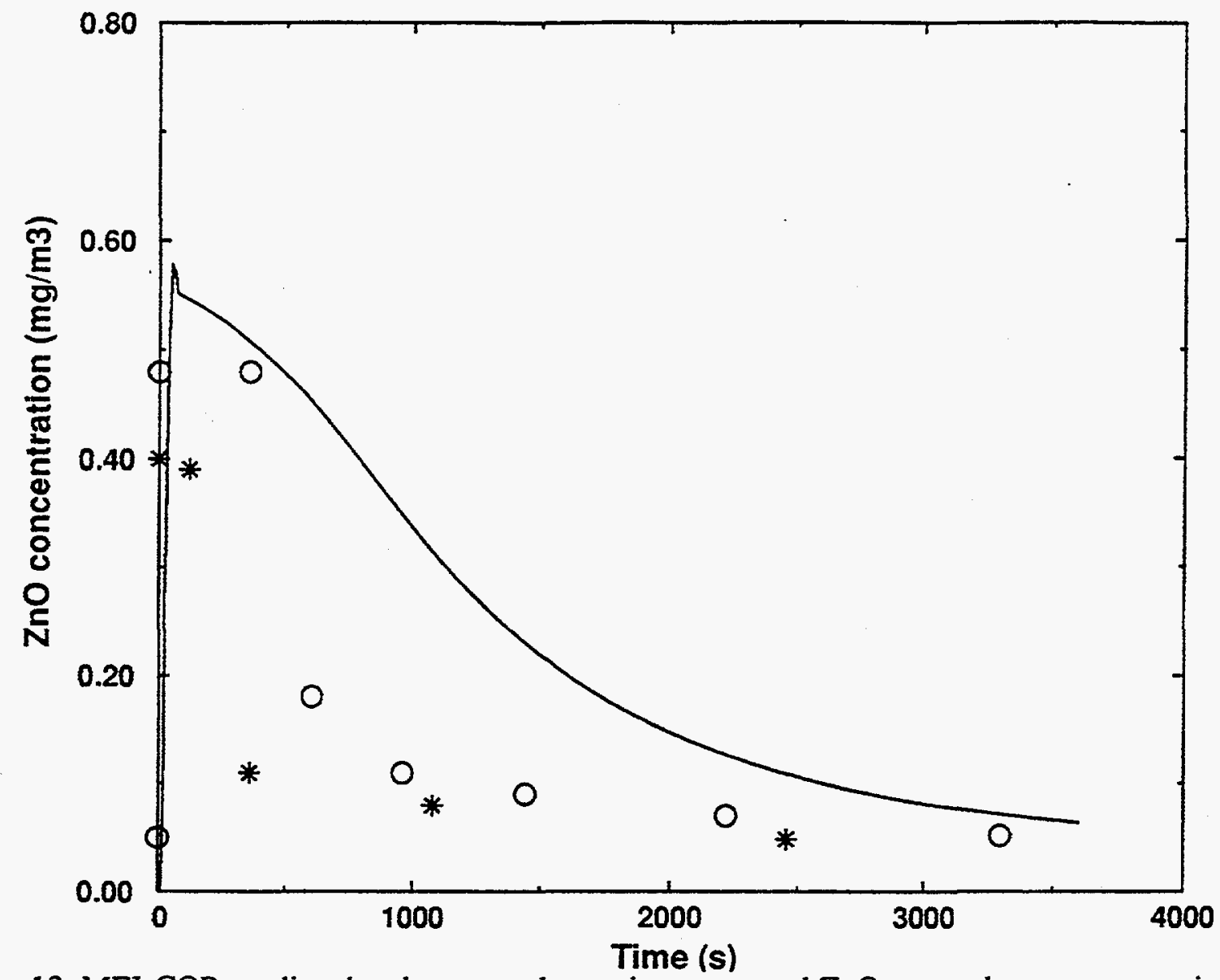

Figure 13. MELCOR predicted and measured containment vessel $\mathrm{ZnO}$ atmosphere concentration for LACE test LA5. 
. 
Appendix A. Estimate of Properties of Materials in LACE Tests 


\section{Appendix A Estimate of Properties of Materials in LACE Tests}

The $\mathrm{NaOH}$ and $\mathrm{CsOH}$ aerosols used in the LACE tests have similar chemical/physical properties. Both have the potential to form sticky aerosol particles and they melt at similar temperatures. (The melting point of $\mathrm{NaOH}$ is $318^{\circ} \mathrm{C}$ and that of $\mathrm{CsOH}$ is $272^{\circ} \mathrm{C}$.) Since the $\mathrm{LA} 3$ tests were above the melting point of $\mathrm{CsOH}$, it is easy to see how the aerosol particles in these tests formed a sticky liquid that caused the high retention factors in tests LA3A - LA3C.

Test LA1 was $25 \mathrm{C}^{\circ}$ below the melting point of $\mathrm{CsOH}$ so melting is not the explanation of the retention in this test. It turns out the $\mathrm{NaOH}$ and $\mathrm{CsOH}$ are both hygroscopic (water absorbing) ${ }^{\mathrm{A} 1}$. The equilibrium vapor pressure of water over a condensed phase of these species is lowered by the species attraction for polar water molecules. Thus even in low relative humidities, water will condense on and dissolve a sample of pure $\mathrm{NaOH}$ or $\mathrm{CsOH}$. The equilibrium water vapor concentration over one of these solutions is a function of the temperature and the solution concentration as shown in Table A1 from Reference 1 . The table gives the activity (i.e. the ratio of the equilibrium water vapor concentration over the solution divided by the equilibrium vapor pressure of water vapor over pure water).

Table A1. Water Activity Data for $\mathrm{CsOH}$ and $\mathrm{NaOH}$ from Jokiniemi.

\begin{tabular}{|c|c|c|c|c|c|}
\hline Mole Fraction & $\mathrm{CsOH}$ & & & & \\
\hline of Salt in Water & $25^{\circ} \mathrm{C}$ & $25^{\circ} \mathrm{C}$ & $60^{\circ} \mathrm{C}$ & $100^{\circ} \mathrm{C}$ & $150^{\circ} \mathrm{C}$ \\
\hline 0.0036 & 0.9934 & 0.9934 & & & \\
\hline 0.0071 & 0.9864 & 0.9866 & & & \\
\hline 0.0106 & 0.9792 & 0.9799 & & & \\
\hline 0.0140 & 0.9718 & 0.9730 & & & \\
\hline 0.0170 & 0.9642 & 0.9661 & & & \\
\hline 0.0210 & 0.9561 & 0.9590 & & & \\
\hline 0.0336 & & 0.9295 & & & \\
\hline 0.0410 & & 0.9094 & & & \\
\hline 0.0418 & & 0.8885 & 0.916 & 0.919 & 0.926 \\
\hline 0.100 & 0.73 & 0.745 & 0.766 & 0.792 & \\
\hline 0.160 & 0.45 & 0.500 & 0.551 & 0.609 & \\
\hline 0.230 & 0.20 & 0.270 & 0.336 & 0.412 & \\
\hline 0.310 & 0.08 & 0.128 & 0.183 & 0.252 & \\
\hline 0.40 & & 0.0626 & 0.0943 & 0.141 & \\
\hline 0.51 & & & 0.0442 & 0.0696 & \\
\hline 0.64 & & & & 0.0267 & \\
\hline
\end{tabular}


At the low temperatures of Tests $\mathrm{CB} 1$ and $\mathrm{CB} 2\left(186{ }^{\circ} \mathrm{C}\right.$ and $111^{\circ} \mathrm{C}$, respectively), the equilibrium concentration of $\mathrm{NaOH}$ in the condensed $\mathrm{NaOH} / \mathrm{H}_{2} \mathrm{O}$ solution was relatively low (we calculate 0.6 mole fraction in $\mathrm{CB} 1$ and 0.24 mole fraction in $\mathrm{CB} 2$ ) and the condensate was similar to water (i.e. not extremely sticky). At the higher temperature of test LA1, the equilibrium concentration of $\mathrm{CsOH}$ in the condensed phase was high (We estimate 0.91 by extrapolating the $\mathrm{NaOH}$ data to high temperature and assuming they apply to $\mathrm{CsOH}$.) and the condensate was sticky. Indirect evidence for increasing stickiness with concentration comes from tables of surface tension versus concentration of $\mathrm{NaOH}$ in the Handbook of Chemistry and Physics ${ }^{\mathrm{A} 2}$ shown below in Table A2.

Table A2. Surface Tension Versus Concentration of $\mathrm{NaOH}$ at $18^{\circ} \mathrm{C}$.

Weight \% Solute $\quad 2.72 \quad 5.66 \quad 16.66 \quad 30.56 \quad 35.9$

$\begin{array}{llllll}\text { Surface Tension } \quad 74.35 & 75.85 & 83.05 & 96.05 & 101.05\end{array}$

(dynes/cm)

The condensate in test $\mathrm{CB} 3$ consisted only of $\mathrm{Al}(\mathrm{OH})_{3}$ which would have remained solid (It changes to $\mathrm{Al}_{2} \mathrm{O}_{3}$ at $300^{\circ} \mathrm{C}$ and $\mathrm{Al}_{2} \mathrm{O}_{3}$ melts at $2054^{\circ} \mathrm{C}^{\mathrm{A}}$ ) and is not reported as a hygroscopic compound. In fact, our equilibrium calculation shows $\mathrm{Al}(\mathrm{OH})_{3}$ gives off an $\mathrm{H}_{2} \mathrm{O}$ molecule at the temperature of test $\mathrm{CB} 3$ to become $\mathrm{AlO}(\mathrm{OH})$. Thus, test $\mathrm{CB} 3$ is the one that is most relevant for ITER ducts with high velocity flows and non-sticky aerosol condensates. (If ITER aerosol condensates are found to be sticky, the deposition fractions would be larger than those for non-sticky material.)

In order to compare the behavior of the LACE test aerosols to the results of calculations with the new models described in this document, it was necessary to estimate the density, surface tension, and viscosity of the aerosol particles in the LACE experiment. The remainder of this appendix describes the methods used to obtain the estimates.

\section{A.1 Particle Composition}

The dry composition of the aerosols produced for each of the LACE tests was given as part of the test specification. This information along with the test temperature and the fact that the partial pressure of steam was 0.5 atmosphere was used to calculate the fraction of water condensed on the aerosol particles.

Table A3 shows the results of the calculation for each of the tests along with the results of some of the intermediate steps. The first column is the test name, the second is the composition of the aerosols used (water was added by absorption from the steam if the dry aerosol particles were hygroscopic), the third is the temperature in ${ }^{\circ} \mathrm{C}$, and the fourth is the mass fraction of the dry materials used to form the aerosol. In the fifth 
Table A3. Aerosol Particle Composition Calculations.

Temperature Dry Mass Dry Mole Hygroscopic Mole Fraction Mass Fraction

Test Aerosol $\left({ }^{\circ} \mathrm{C}\right) \quad$ Fraction Fraction Mole Fraction

\begin{tabular}{|c|c|c|c|c|c|c|c|}
\hline CB1 & $\begin{array}{l}\mathrm{NaOH} \\
+\mathrm{H}_{2} \mathrm{O}\end{array}$ & 186 & 1 & 1 & $\begin{array}{l}0.63 \\
0.37\end{array}$ & $\begin{array}{l}0.63 \\
0.37\end{array}$ & $\begin{array}{l}0.79 \\
0.21\end{array}$ \\
\hline CB2 & $\begin{array}{l}\mathrm{NaOH} \\
+\mathrm{H}_{2} \mathrm{O} \\
\mathrm{Al}(\mathrm{OH})_{3}\end{array}$ & 111 & $\begin{array}{l}0.67 \\
0.33\end{array}$ & $\begin{array}{l}0.80 \\
0.20\end{array}$ & $\begin{array}{l}0.24 \\
0.77\end{array}$ & $\begin{array}{l}0.496 \\
0.379 \\
0.125\end{array}$ & $\begin{array}{l}0.54 \\
0.19 \\
0.27\end{array}$ \\
\hline CB3 & $\mathrm{Al}(\mathrm{OH})_{3}$ & 160 & 0 & & & 1 & 1 \\
\hline LA1 & $\begin{array}{l}\mathrm{CsOH} \\
+\mathrm{H}_{2} \mathrm{O} \\
\mathrm{MnO}\end{array}$ & 247 & $\begin{array}{l}0.42 \\
0.58\end{array}$ & $\begin{array}{l}0.26 \\
0.74\end{array}$ & $\begin{array}{c}0.91 \\
0.09\end{array}$ & $\begin{array}{l}0.25 \\
0.02 \\
0.73\end{array}$ & $\begin{array}{l}0.42 \\
0.005 \\
0.58\end{array}$ \\
\hline LA3A & $\begin{array}{l}\mathrm{CsOH} \\
+\mathrm{H}_{2} \mathrm{O} \\
\mathrm{MnO}\end{array}$ & 298 & $\begin{array}{l}0.18 \\
0.82\end{array}$ & $\begin{array}{l}0.09 \\
0.91\end{array}$ & $\begin{array}{l}>0.99 \\
<0.01\end{array}$ & $\begin{array}{l}0.09 \\
0.0009 \\
0.91\end{array}$ & $\begin{array}{l}0.18 \\
0.0002 \\
0.82\end{array}$ \\
\hline LA3B & $\begin{aligned} & \mathrm{CsOH} \\
&+ \mathrm{H}_{2} \mathrm{O} \\
& \mathrm{MnO}\end{aligned}$ & 303 & $\begin{array}{l}0.12 \\
0.88\end{array}$ & 0.06 & $\begin{array}{l}>0.99 \\
<0.01\end{array}$ & $\begin{array}{l}0.06 \\
0.0006 \\
0.94\end{array}$ & $\begin{array}{l}0.12 \\
0.0001 \\
0.88\end{array}$ \\
\hline LA3C & $\begin{aligned} & \mathrm{CsOH} \\
&+ \mathrm{H}_{2} \mathrm{O} \\
& \mathrm{MnO}\end{aligned}$ & 300 & $\begin{array}{l}0.38 \\
0.62\end{array}$ & 0.22 & $\begin{array}{l}>0.99 \\
<0.01\end{array}$ & $\begin{array}{l}0.224 \\
0.002 \\
0.774\end{array}$ & $\begin{array}{l}0.38 \\
0.0004 \\
0.62\end{array}$ \\
\hline
\end{tabular}

column are the results of calculating the mole fraction of these materials from the mass fractions using the relation,

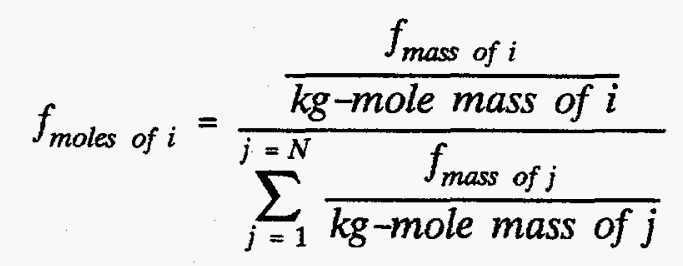

The sixth column shows the result of calculating the mole fractions of the hygroscopic compound $(\mathrm{NaOH}$ or $\mathrm{CsOH})$ and water in the condensed phase without considering any other compounds that may be present. This was done using a double fit to the data of 
Jokiniemi as outlined below:

First the activities versus temperature for three mole fractions were fit using linear relationships,

$$
\text { Activity }=A+B \text { Temperature }
$$

These expressions were used to extend or interpolate the data to the test temperature of interest at $0.27,0.128$, and 0.026 mole fraction.

Second, the calculated activities at temperature were fit using a log-linear relation,

$$
\ln (\text { Activity })=C+D f_{\text {mole of hygroscopic compound }}
$$

Third, the activity (i.e. the steam pressure over the equilibrium steam pressure) was calculated from steam tables and used to calculate the mole fraction of the hygroscopic species at equilibrium for the temperature. The saturated steam pressures and activities obtained in this step are listed in Table 4

The seventh column of Table A3 adds the non-hygroscopic components to the calculation of the total mole fraction. The expression used to calculate this fraction was derived by imagining there is one mole of dry material consisting of $f_{\text {mole dry }} \mathrm{CsOH}, \mathrm{NaOH}$ and $\mathrm{f}_{\text {mole dry insoluble. }}$. The amount of water added to this dry mole is the product of the number of moles of dry hygroscopic material and the equilibrium mole fraction of water in a solution of the hygroscopic material and water, i.e. $f_{\text {mole dry } \mathrm{CsOH}, \mathrm{NaOH}}$ times $\mathrm{f}_{\text {mole }}$ hygroscopic. Thus

$$
\begin{aligned}
& f_{\text {mole } \mathrm{NaOH}, \mathrm{CsOH}}= \\
& f_{\text {mole dry } \mathrm{NaOH}, \mathrm{CsOH}}
\end{aligned}
$$

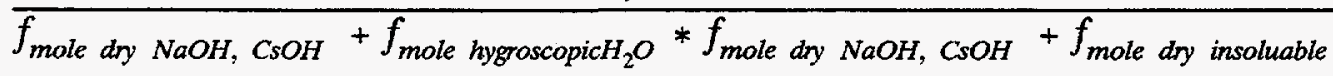

$$
\begin{aligned}
& f_{\text {mole } \mathrm{H}_{2} \mathrm{O}}= \\
& f_{\text {mole hygroscopich } \mathrm{H}_{2} \mathrm{O}} * f_{\text {mole dry } \mathrm{NaOH}, \mathrm{CsOH}}
\end{aligned}
$$

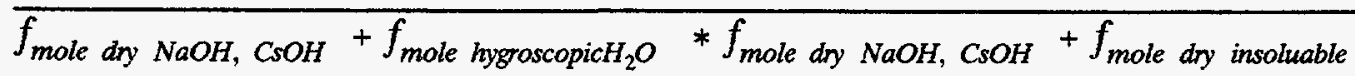


$f_{\text {mole insoluable }}=$

(A6)

$f_{\text {mole dn insoluable }}$

$\overline{f_{\text {mole dry } \mathrm{NaOH}, \mathrm{CsOH}}+f_{\text {mole hygroscopich }} \mathrm{O} * f_{\text {mole dry } \mathrm{NaOH}, \mathrm{CsOH}}+f_{\text {mole dry insoluable }}}$

Table A4. Saturated steam pressures and activities obtained during the third step.

Saturation

Temperature Pressure Hygroscopic

Test Aerosol $\left({ }^{\circ} \mathrm{C}\right) \quad$ (Bar) Activity Mole Fraction

$\begin{array}{llllll}\mathrm{CB} 1 & \mathrm{NaOH} & 186 & 11.488 & 0.0435 & 0.63\end{array}$

$+\mathrm{H}_{2} \mathrm{O} \quad 0.37$

$\begin{array}{llllll}\mathrm{CB} 2 & \mathrm{NaOH} & 111 & 1.4814 & 0.3375 & 0.24\end{array}$

$+\mathrm{H}_{2} \mathrm{O}$

$\mathrm{Al}(\mathrm{OH})_{3}$

0.77

$\begin{array}{lll}\mathrm{CB} 3 & \mathrm{Al}(\mathrm{OH})_{3} & 160\end{array}$

$\begin{array}{llllll}\mathrm{LA} 1 & \mathrm{CsOH} & 247 & 37.799 & 0.0133 & 0.91 \\ & +\mathrm{H}_{2} \mathrm{O} & & & & 0.09 \\ & \mathrm{MnO} & & & & \end{array}$

$\begin{array}{llllll}\text { LA3A } & \mathrm{CsOH} & 298 & 83.52 & 0.00599 & >0.99\end{array}$

$+\mathrm{H}_{2} \mathrm{O}$

$\mathrm{MnO}$

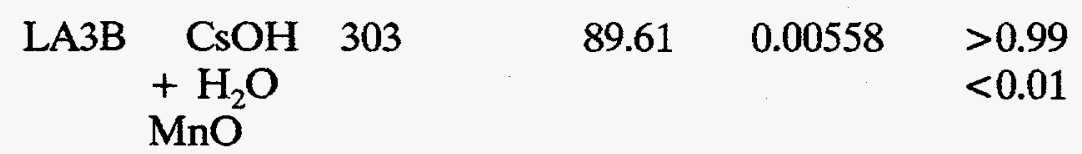

LA3C $\begin{array}{ccccc}\mathrm{CsOH} & 300 & 85.92 & 0.00582 & >0.99 \\ +\mathrm{H}_{2} \mathrm{O} & & & & <0.01\end{array}$

$\mathrm{MnO}_{2}$

The eighth column of Table A3 is the mass fraction of each component calculated from the mole fraction with the expression 


$$
f_{\text {mass of } i}=\frac{f_{\text {mole of } i} * k g \text {-mole mass of } i}{\sum_{j=1}^{j=N} f_{\text {mole of } j} * k g \text {-mole mass of } j}
$$

\section{A.2 Condensed Phase Densities}

The density of the condensed phase in $\mathrm{kg}$-moles $/ \mathrm{m}^{3}$ was calculated from the densities of the component species by adding the volume of each component species in a $\mathrm{kg}$-mole of mixture to determine the volume of one mole of the mixture,

$$
V_{k g-\text { mole }}=\sum_{j=1}^{N} f_{\text {mole of } i} *\left[V_{i}=\frac{1}{\rho_{i}}\right] * \text { kg-mole mass of } j
$$

and dividing it by the mass in a $\mathrm{kg}$-mole of the mixture,

$$
M_{\text {mole }}=\sum_{j=1}^{N} f_{\text {mole of } i} * k g \text {-mole mass of } j
$$

to find

$$
\rho_{\text {mix }}=\frac{\sum_{j=1}^{N} f_{\text {mole of } j} * k g \text {-mole mass of } j}{\sum_{j=1}^{N} \frac{f_{\text {mole of } j} * k g \text {-mole mass of } j}{\rho_{j}}}
$$

The kg-mole masses and densities of the component species used in the calculations are listed in Table A5 and the resultant densities of the condensates in the tests are listed in Table A6.

Table A5. Kg-Molar Masses and Densities of Component Species.

Species

Kg-Molar Mass

(kg/kg-mole)
$\mathrm{NaOH}$

$\mathrm{CsOH}$

39.99707

149.9127

$\mathrm{Al}(\mathrm{OH})_{3} \quad \mathrm{MnO}$

$\mathrm{H}_{2} \mathrm{O}$

$78.00344 \quad 70.94$

18.0152 
Table A6. Condensate Densities.

$\begin{array}{lccccccc}\text { Test } & \text { CB1 } & \text { CB2 } & \text { CB3 } & \text { LA1 } & \text { LA3A } & \text { LA3B } & \text { LA3C } \\ \begin{array}{l}\text { Density } \\ \left(\mathrm{kg} / \mathrm{m}^{3}\right)\end{array} & 1722 & 1821 & 2530 & 4428 & 4954 & 5085 & 4562\end{array}$

\section{A.3 Surface Tension of Condensates}

The surface tension estimates for the condensates are based on a double fit to (1) data showing changes in the surface tension of a solution of water and $\mathrm{NaOH}$ at $18^{\circ} \mathrm{C}^{\mathrm{A} 2}$ versus the concentration of $\mathrm{NaOH}$ and (2) another set of data ${ }^{\mathrm{A} 4}$ showing the change of the surface tension of water with temperature. The expressions for the surface tension were obtained by multiplying the surface tension for water as a function of temperature times the fractional change in the surface tension with increasing $\mathrm{NaOH}$ or $\mathrm{CsOH}$ :

$$
\begin{aligned}
& \sigma \mathrm{mix}= \\
& {\left[0.075887-0.0001646751 \mathrm{~T}\left({ }^{\circ} \mathrm{C}\right)\right]\left[0.991359+1.931524 f_{\text {mole hyg }}\right] \mathrm{N} / \mathrm{m}}
\end{aligned}
$$

The resultant estimates for the surface tensions of the condensates in the tests are listed in Table A7.

Table A7. Condensate Surface Tensions.

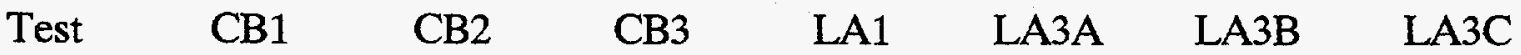

$\begin{array}{llllllll}\text { Surface } & 0.100 & 0.083 & - & 0.097 & 0.078 & 0.075 & 0.077\end{array}$

Tension

$(\mathrm{N} / \mathrm{m})$

\section{A.4 Viscosities of Condensates}

The viscosity estimates for the condensates are based on a theoretical expression for the viscosity of a pure substance versus temperature from Bird, Stewart, and Lightfoot ${ }^{\mathrm{A} 5}$, on data for the viscosity of water, and on an empirical expression for the viscosity of a mixture of liquids. According to pages 26-30 of Bird, Stewart, and Lightfoot, 


$$
\mu=\frac{N_{A \nu} h}{V_{\text {mole }}} \exp \left(\frac{3.8 T_{b}}{T}\right)
$$

where

$$
\begin{aligned}
& \mathrm{N}_{\mathrm{Av}}=\text { Avagadro's number, } 6.02 \times 10^{26} \text { atoms } / \mathrm{kg}-\mathrm{mole} \\
& \mathrm{h}=\text { Plank's constant, } 6.624 \times 10^{-34} \mathrm{~kg} \mathrm{~m}^{2} / \mathrm{s} \\
& \mathrm{V}_{\text {mole }}=\text { the molar volume of the species, (estimated by } \\
& \mathrm{kg} \text {-mole mass over the density of the condensed } \\
& \text { phase) } \\
& \mathrm{T}_{\mathrm{b}}=\text { boiling temperature of the chemical species }(\mathrm{K})
\end{aligned}
$$

The boiling temperatures of $\mathrm{NaOH}$ and $\mathrm{CsOH}$ are not available because they disassociate before boiling. Thus, the following expressions for the vapor pressure to calculate a theoretical boiling temperature of $1347 \mathrm{~K}$ for $\mathrm{CsOH}$ and $1653 \mathrm{~K}$ for $\mathrm{NaOH}$.

$$
\begin{aligned}
& P_{e q}(\mathrm{CsOH})=\exp ^{\left(\frac{-14,769}{T}+22.49\right)} P a \\
& P_{e q}(\mathrm{NaOH})=\exp ^{\left(\frac{-7,520}{T}+9.5549\right)} P a
\end{aligned}
$$

The form of the correlation for the variation of viscosity as two components are mixed is based on a correlation presented in the 42rd edition of the Handbook of Chemistry and Physics $^{\mathrm{A} 6}$ for the viscosity of mixtures of Glycerol and water. The form of the handbook correlation is

$$
\ln \left(\frac{\mu}{\mu_{H_{2} \mathrm{O}}}\right)=\text { constant } x^{2}
$$

where

$$
\begin{aligned}
& \mu \quad=\quad \begin{array}{l}
\text { viscosity of the solution }(\mathrm{kg} / \mathrm{m}-\mathrm{s}) \\
\text { viscosity of water at the temperature of interest } \\
(\mathrm{kg} / \mathrm{m}-\mathrm{s})
\end{array} \\
& \mathrm{x} \quad=\quad \text { mole fraction of the component that is not water }
\end{aligned}
$$


This expression was applied to the case of solutions of $\mathrm{CsOH}$ or $\mathrm{NaOH}$ and water. The result is

$$
\mu=\mu_{\mathrm{H}_{2} \mathrm{O}}(T) \exp \left[\ln \left(\frac{\mu_{\mathrm{COOHNOOH}}(T)}{\mu_{\mathrm{H}_{2} \mathrm{O}}(T)}\right) x^{2}\right]
$$

The resultant estimates for the viscosities of the condensates in the tests are listed in Table A8.

Table A8. Condensate Viscosities.

$\begin{array}{lllllll}\text { Test } & \text { CB1 } & \text { CB2 } & \text { CB3 } & \text { LA1 } & \text { LA3A } & \text { LA3B }\end{array}$

$\begin{array}{llllllll}\text { Viscosity } & 0.0169 & 0.00551 & - & 0.0505 & 0.0665 & 0.0617 & 0.0646\end{array}$ $(\mathrm{kg} / \mathrm{m}-\mathrm{s})$ 


\section{A.5 Appendix A References}

A1. Jorma Jokiniemi, "The Growth of Hygroscopic Particles during Severe Core Melt Accidents," Nuclear Technology 83, pp. 16-23, October 1988.

A2. Handbook of Chemistry and Physics, 60 th edition.

A3. John A. Dean, Lange's Handbook of Chemistry. Fourteenth Edition, New York: McGraw-Hill, Inc., 1992.

A4. Charles D. Hodgman (ed.), Handbook of Chemistry and Physics. 38 th edition, 1956, page 2016.

A5. R. Byron Bird, Warren E. Stewart, and Edwin N. Lightfoot, Transport Phenomena, New York: John Wiley \& Sons, 1960.

A6. Charles D. Hodgman (ed.), Handbook of Chemistry and Physics. 43rd edition, 1961. 

Appendix B

Listing of Fortran Coding for Modifications of MELCOR 
MODIFICATIONS TO SUBROUTINE RN1DB1

(1ine numbers are relative to file $\mathrm{xn} 1 \mathrm{db} 1 . f$ )

LINES ADDED AFTER LINE 631

$$
++8 * \text { MnVOL }
$$

omig add last addition term to NUSREL oaloulation

MODIFICATIONS TO SUBROUTINE RN1P1B

(1ine numbers are relative to file rniplb.f)

CHANGED LINE 54 FROM

+ IFLAGR, IFLAG, IGOOD, IACTV) TO

+ IFLAGR, IFLAG, IGOOD, IACTV, IDBMAR

< cmig + IFLAGR, IFLAG, IGOOD, IACTV)

ChANGED IINE 70 FROM

+ HSATP (MNUNHS), IHSGEO (NNUMHS)

TO

+ HSAIP (MNUMHS), IHSGEO (MNUMHS), TDBMAR (8, NVOL

onig

+ HSATP (MNUMMS) , IHSGEO (MNUMHS)

ADDED AFTER LINE 1896

cmig-

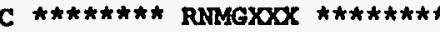

c

a-

BEND AND TURBULENT DEPOSITION

Inftialize array

do 1987 1fh $=1$, NVOL

$1987 \operatorname{TDBMAR}(1,1 \mathrm{jh})=-1.0$

IDNUM $=7$

IDSNUM $=4$

IDWANT $=$ ' RNMG

INSW $=1$

1859 CAIN CRACKR

INSW $=2$

IF (IOUTSW.GE.3) GO TO 1509

\section{IF (IOUTSW. EQ.1) THEN}

CHECK NUMBER OF FIELDS AND DATA TYPES

DO $1559 I=1,3,2$

IF(IGOT(I) .EQ.0) GO TO 1559

CALI MESERA (CHERRR,' ',', 0 )

FRITE (NOUT, 1020) IDGOT, I

WRITE (NDIAG, 1020) IDGOT, I IGOOD $\approx 1$

CONTINUE

DO $3609 I=2,2$

IF (IGOT (I) .EQ:-1) GO TO 3609

CALL MESERA (ChERRR,' ', , ,0)

FRITE (NOUT, 1020) IDGOT, I

WRITE (NDIAG, 1020) IDGOT, I $I G O O D=1$

CONTINUE

DO $1609 I=4,6$

IF (IGOT (I) .EQ. -1) GO TO 1609

CALL MESERA (CHERRR,' $, ', 0$ )

WRITE (NOUT, 1020) IDGOT, I

WRITE (NDIAG, 1020) IDGOT, I

$I G O O D=1$

CONIINUR

CHECK TO SEE IF VOLUME IS DEFINED IN CVH DATABASE

\section{IXVOL=INTEG $(1)$}

$I=1$

DO $1619 I X=1$, NVOL

IF (IXVOL.EQ.ICWNUM(IX)) GO TO 1629 CONTINUE

CALL MESERA (CHERRR, $,, 1,0)$.

WRITE (NOUT, 1030) IDGOT, I

WRITE (NDIAG, 1030) IDGOT, I

$I G O O D=1$

$I X=1$

CONTINUE

IVOL $=I X$

ASSIGN VARIABLE NAME TO INPUT DATA 
$\operatorname{TDBMAR}(1, \operatorname{IVOL})=1.0$

TDBMAR (2, IVOL) =REAL, (INTEG (1)

$\operatorname{TDBMAR}(3$, IVOL) $=$ REALV (2)

$\operatorname{TDBMAR}(4$, IVOL) $=\operatorname{REAL}$ (INTEG (3))

TDBMAR (5, IVOL) =REALV (4)

$\operatorname{TDBMAR}(6$, IVOL) $=\operatorname{REALV}(5)$

TDBMAR (7, IVOL) =REALV (6)

$\operatorname{TDBMAR}(8$, IVOL) $=$ REALV (7)

ELSE

CAII MESERA (CHERRR, ', ', 0)

WRITE (NOUT, 1040) IDGOT

WRITE (NDIAG, 1040) IDGOT $I G O O D=1$

END IF

GO TO 1859

1509

CONTINUE

cmig

C

\section{MODIFICATIONS TO SUBROUTINE RN1DBZ}

(line numbers are relative to flle rnidbz.f)

$-\cdots$

IINES ADDED AFTER LINE 599

cmlg advance IRNEXT by additional storage IRNEXT = IRNEXT + 8*NNVOL

cmig

LINES ADDED AFTER LINE 765

IMG $=I R-8 *$ NNVOL +1

omig add polnter to beginning of last part of XRN1

(1)

UINE 789 CHANGED FROM

NNUMHS, XRN1 (ICVPTH) , NGAPC, MAX (1, NGAPC), IFLAGR, IFLAG, IGOOD, IACTV) To

$+$

NNUMHS, XRN1 (ICVPTH), NGAPC, MAX (1, NGAPC), IFLAGR, IFLAG, IGOOD, IACTV, $+\operatorname{XRN1}$ (IMG))

Conlg + NNUMHS, XRN1 (ICVPTH), NGAPC, MAX (1, NGAPC), IFLAGR, IFLAG, IGOOD, IACTV)
MODIFICATIONS TO SUBROUTINR RN1DBD

(IIne numbers are relative to file rnidbd.f)

LINE 679 CHANGED FROM

$+\mathrm{XCV}(\mathrm{KCVVOO}+\mathrm{IC})$, NUMHS, NNUMHS, IHS (NHSNUM) , XHS (NHSMLN-IH),

$+\mathrm{XCV}(\mathrm{KCVVOO}+\mathrm{IC}), \mathrm{XCV}(\mathrm{KCVVL} O+\mathrm{IC}), \mathrm{NCVVZ}, \mathrm{ICV}$ (KCVVZP) , XCV (KCVZ)

+ NUMHS, MNUMHS, IHS (NHSNUM) , XHS (NHSMLN-IH)

LINE 686 CHANGED FROM

$+\operatorname{ISC}($ IPI4), ISC (IPI8), ISC (IPI9), ISC (IPI11), ISC (IPI12))

$+\operatorname{ISC}($ IPI4),ISC (IPI8), ISC(IPI9), ISC (IPI11), ISC (IPI12)

$+\operatorname{XRN1}$ (IRRN1-8*NNVOL+1))

cmig + ISC(IPI4),ISC(IPI8),ISC (IPI9),ISC(IPI11),ISC (IPI12))

MODIFICATIONS TO SUBROUTINE RN1RN4

(1ine numbers are relative to file rnirn4.f)

LINE 15 CHAMGED FROM

$+$

PVOL, TVOL, CVOL, NUMHS, MNUMHS, IHSNUM, HSMULT, FIIMLO, FILMRO, HSMCMN To

+ PVOL, TVOL, CVOL, CVVELO, NCVVZ, ICVVZP, CVZ,

+ NUMHS, NNUMHS, IHSNUM, HSMULT, FILMLO, FILMRO, HSMCMN,

LINE 18 CHANGED FROM

+ HSMRRN, WDER, WCOND, IWORK, IG, IAERG, NHS, IERRX, IZ, IZO)

+ HSMTRN, WDEP, WCOND, IWORK, IG, IARRG, NHS, IRRRX, IZ, IZO, TDBMAR)

LINE 23 CHANGED FROM

+ IVDS (NVOL), IDSUR (4, NNSUR),

+ IVDS (NVOL), IDSUR (4, MNSUR), CVVRLO (2, NVOL)

LINE 39 CHANGED FROM

+ CVZPOL (NVOL), CVAPOL (NVOL)

TO

+ CVZPOL (NVOL) , CVAPOL (NVOL) , CVZ (NCVVZ), ICVVZP (NVOL+1) 
LINE 42 CHANGED FROM

+ ETRANS (NVOL)

+ ETRANS (NVOL) , TDBMAR (8, NVOL)

LINES ADDED AFTER LINE 42

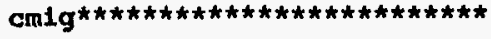

c array TDBMAR (8, NVOL) (turbulent bend deposition array)

c contains the following

c Index 1: flag for valid info:

$\circ$

Inder 2: aatuel volume td

Index 3: characteristic dimension (1.e. pipe diameter)

Index 4: number of bends in the bend model

Index 5: turning angle of the bends (radlans)

index 6: oross-sectional area over deposition area (bend deposition)

- Index 7: surface roughness for turbulent depostion model

c Index 8: ourface stioking factor

LINE ADDED AFTER LINE 49

COMMON / RESUSP / BOIL2 (999), , ZB2 (999)

C

LINES ADDED AFTER LINE 309

$C * *$ * ACCOUNT FOR RESUSPENSION BY BOILING

DO $13 \mathrm{~N}=1$, NVOI

IF (BOIL2 (N) . GE.0.0) GO TO 13

ISTAR $=$ ICVVZP $(\mathrm{N})$

DZPOOL $=$ CVZPOL $(N)-$ CVZ (ISTAR)

DPART $=(3 . *(X M M E C(1)+\operatorname{XOSSEC}(2)) /$ RHONOM/PI $) * *(1 . / 3$.

SE = BUBDE (DPART, $\operatorname{TVOL}(1, N)$, PVOL (N), DT, RHONOM, DZPOOL

CVAPOL (N), BOTL2 (N))

DO $14 x=1$, NCLS

IF (ARRILN (K, N) .LE. 0.0) GO TO 14

FRACRL $=\operatorname{MAX}(-1,0, \operatorname{BOIL2}(\mathrm{N}) / \operatorname{XMASS}(1, N)$

DARRLN $=$ FRACRL $*$ AERLLN $(K, N) \star$ SF

AERILN $(K, N)=\operatorname{MAX}(0, A$ ABRILN $(K, N)+D A E R L N)$

$\operatorname{AERIGN}(1, K, N)=\operatorname{MAX}(0, \operatorname{ARRIGN}(1, K, N)-\operatorname{DARRLN})$

14 CONTINUE

13 CONTINUE

LINES 412 -431 CHANGED EROM

c

GET BULK DENSITY AND DIFEUSIOPHORESIS FACTOR

XMSTM $=$ XMASS $(3, M)$

XMGAS $=$ ZERO

DO $390 \quad I=4$, NMAT

XMGAS $=$ XMGAS + XMASS $(I, N)$

390 CONTINUE

RHOBLK = (XMGAS + XMSTM) / VOLUME

CALL H2OSAT (1, TSAT, PVOL (N) , RLIQ, RHOSTM, IERR)

FTST $=1000 . \mathrm{DO} * \mathrm{KM}(3)$

XMOLES $=$ XMSTM $/$ FTST

XMOLEG $=$ XMGAS / FTMOL

XMOLET $=$ XMOLES + XMOLEG

XMS $=$ XMOLES / XMOLET

$\mathrm{XMA}=1.0 \mathrm{DO}-\mathrm{XMS}$

XDIFFI $=$ SQRT (WTST) $/($ XMS * SQRT (HTST) + XMA * SQRT (WTMOL $)$

VGAS $=\operatorname{CVVELO}(2, N)$

NUMVISX $=5$

CALI, MPEVAT (NUMVISX, XMASS $(1, \mathrm{~N})$, ICNCRN, 3, NMAT, ' CVH',

1 MMAT, PDUM, TVOL $(2, N)$, VISGAS, IGERR

GET BULK DENSITY AND DIFFUSTOPHORESIS FACTOR

XUSTM $=\operatorname{xMASS}(3, N)$

XOMGAS $=$ ZERO

XMNOLS $=$ ZERO

DO $390 I=4$, NMAT

XMGAS $=$ XMGAS + XMASS $(I, N)$

XMOLS $=$ XMOLS + XMASS $(I, N) /$ WM(I)

CONTINUE

WMGAS = FTMOI

IF (XMOLS. GT.ZERO) THEN

TMGAS $=$ ZERO 
DO 395 I=4, NMAT

WMGAS $=$ MMGAS $+1000 . \star$ XMASS $(I, N) /$ XMOLS

395 CONTINUE

ENDIF

c

RHOBLK $=$ (XMGAS + XMSTM) $/$ VOLUME

CALL H2OSAT (1, TSAT, PVOL (N) , RLIQ, RHOSTM, IERR)

c

WTST $=1000 . \mathrm{DO} *$ WM(3)

XMOLES $=$ XMSTM / WTST

XMOLEG = XMGAS $/$ MMGAS

XMOLET = XMOLES + KMOLEG

XOMS = XMOLES / XMOLET

$\operatorname{XMA}=1.000-X \mathrm{XMS}$

XDIFEI $=$ SQRT (WTST) $/$ (XMS * SQRT (WTST) + XMA * SQRT (MMGAS))

FMGAS = XMS*FIST + XMA*FMGAS

LINES 533-534 CHANGED FROM

DO 445 I=ISUM, ISUMP

445 AREAHS (I) =AREAHS (I) / VOLUME

DERSUM $=0.0$

DEPARA $=0.0$

DO 445 I=ISUM, ISUNP

DEPARA = DERARA + AREAHS $(I)$

DO 446 J $=1$, NCLS

446

DEPSUM $=\operatorname{DEPSUM}+\operatorname{ADERN}(J, I)$

445 AREAHS ( $I$ ) =AREAHS ( $I$ ) /VOLUME

DQMIN $=(3 . *($ XMSEC $(1)+\operatorname{XMSEC}(2)) /$ RHONOM/PI $) * *(1 . / 3$.

DEPHGT $=$ DEPSUM/RHONOM/DEPARA

LINES ADDED AFTER 562

DPART $=(3 . *($ XMSEC $(L)+\operatorname{XMSEC}(L+1)) /$ RHONOM/PI $) * *(1 . / 3$.

GRAVITY

GRAVDEP = FGRAV (TVOL $(2, N)$, RHOBLK, VISGAS, WMGAS, DPART, RHONOM)

array TDBMAR (8, NVOL) (turbulent bend deposition array)

contains the following

Index 1: flag for valid info:

$$
-I=1 \text { invalid entry }
$$$$
\text { lavalid entry }
$$

c Index 2: actual volume id

c Index 3: characteristic dimension (1.e. plpe diameter)

a Index 4: number of bends in the bend model

- Index 5: turning angle of the bends (radians)

c Index 6: cross-sectional area over deposition area (bend deposition)

c Index 7: surface roughness for turbulent depostion model

c Index 8: surface sticking factor

BENDDER $=0.0$

IF (TDBMAR (4,N) , GT . 0.0) THEN

$S R=\operatorname{MAX}(\operatorname{TDBMAR}(7, \mathrm{~N})-\mathrm{DEPHGT}, \mathrm{DPMTN})$

DELELM $=$ MAX(DEPHGT, 0.0$)$

ACOVRAS $=P I * T D B M A R(3, N) * * 2 /(4, *$ VOLUMR $)$

BENDDEP = FBEND ( VGAS, DPART, VISGAS, RHONOM, $\operatorname{TDBMAR}(3, \mathrm{~N})$

., tdamar $(4, N), \operatorname{TdbMar}(5, N), \operatorname{ACOVRAS}, \operatorname{TdbMar}(6, N)$

.. TDBMAR $(\theta, N)$, RHOBLK, DELFLM)

TURBDEP $=0.0$

ENDIF

SFTURB $=1.0$

IF (TDBMAR (7, N) . GT . 0.0) THEN

$\mathrm{SR}=\operatorname{MAX}(\operatorname{TDBMAR}(7, N)-\mathrm{DEPHGT}, \mathrm{DPMIN})$

DELFLM $=\operatorname{MAX}(D E P H G T, 0.0)$

TURBDER $=$ FTURB $($ VGAS, DPART, VISGAS, RHONOM, TVOL $(2, N)$, RHOBLK

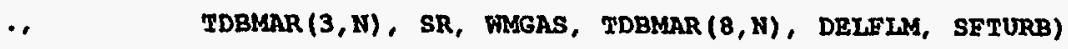

C * * THERMORHORESTS COEEETCIENT

THRMDEP $=\operatorname{ETHRM}(T V O L(2, N)$, RHOBLK, VISGAS, KMGAS, DRART)

C * * DIFFUsION

C

DIFFDEP $=$ FDIFF $(T V O L(2, w)$, RHOBLK, VISGAS, WMGAS, DPART $)$

c

C * * CHECK FOR EXCESS PARTICLE MOMENTUM

c

C

-.-

LINES 568-602 CHANGED FROM

IF (IND.EQ.1) THEN

AKRRWL $=-$ COEFAV (L3ML +3)

ELSE IF (IND.EQ.2) THEN

AKERNL $=$ ZERO 
ELSE IF (IND.EQ.3) THEN

AKERNL $=\operatorname{COEFAV~}($ L3M1+3)

ELSE

AKERNL $=2$ ERO

END IF

IF (WCOND (I) , GE . ZERO) THEN

DIEFIO = XOIFEI * WCOND(I) / RHOBLK

ELSE

DIFEIO $=$ WCOND (I) / RHOSTM

END IF

AKERNL $=$ AKERNL + COEEAV $(L 3 M 1+1)$

$+\quad+\operatorname{TGRAD}(I)$ *COEFAV $($ L $3 M 1+2)$

$+\quad+$ DIFETO

AKERNL $=$ MAX (ZERO, AKERNL)

TDPCOF (L) = TDPCOF (L) +AREAHS (I) *AKERNL CONTrNUE

Poor

\section{DIFFIO=2ERO}

AKRRNL $=\operatorname{COEFAV~}(L 3 M 1+3)+\operatorname{COEFAV}(L 3 M 1+1)$

$+\quad$ +TGRADP *COEFAV (L3M1+2)

+DIFrIO

AKERNL $=\operatorname{MAX}($ ZERO, AKRRNL)

TDPCOF $(L)=$ TDPCOF $(L)$ +AREAP *AKCERNL

\section{FLOWTHRUS}

ARERNI = COEFAV $(23 M 1+3)+\operatorname{COEFAV}(L 3 M 1+1)$

AKERNL = $M A X$ (ZERO, AKERNL)

TDPCOF $(L)=$ TDPCOF (L) + ATHRU *AKRRNL

$$
\text { To }
$$

\section{GRAVITY}

IF (IND.EQ.1) THEN

AKERNL $=$ - GRAVDEP

ELSE IF (IND.EQ.2) THEN

AKERNL = ZERO

ELSE IF (IND.EQ.3) THEN

AKRRWL $=$ GRAVDEP

ELSE

AKCERH $=$ ZERO

END IF

IF (HCOND (I) . GE . ZERO) TKEN

DIFETO $=$ XDIFEI * WCOND $(I) /$ RHOBLK

ELSE

DIFEIO $=$ WCOND $(I) /$ RHOSTM

END IF

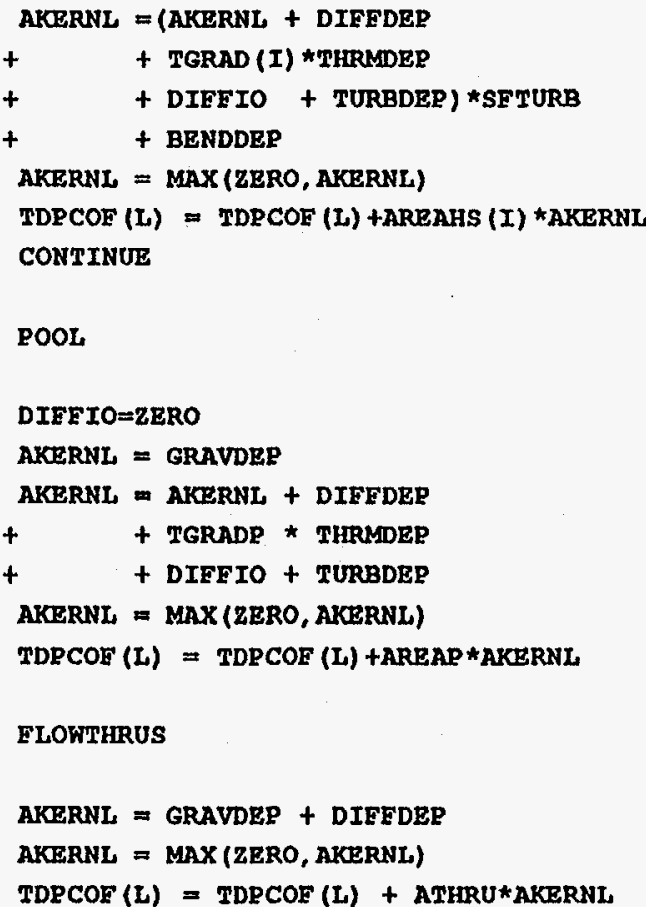

\author{
GRAVDEP = FGRAV (TVOL (2, N), RHOBLK, VISGAS, WMGAS, DRART, RHONOM)
}

array TDBMAR (8, NVOL) (turbulent bend deposition array) 
c Index 7: aurface roughness for turbulent depostion model

c Index 8: ourface stioking factor

BENDDEP $=0.0$

$\operatorname{IF}(\operatorname{TDAMAR}(4, N), G T .0 .0)$ THEN

$S R=\operatorname{MAX}(T D B M A R(7, N)-D E P H G T, D P M I N)$

DELFLM $=$ MAX (DEPHGT, 0.0)

ACOVRAS $=2 I * \operatorname{TDBMAR}(3, \mathrm{~N}) \star \star 2 /(4, \star$ VOLUMR $)$

BENDDEP = FBEND ( VGAS, DPART, VISGAS, RHONOM, $\operatorname{TDBMAR}(3, N)$

. $\operatorname{Tdmar}(4, N), \operatorname{TdBmar}(5, N), \operatorname{Acovras,} \operatorname{tabmar}(6, N)$

. TDBMar (8,N), RHOBLK, DELFLM)

TURBDEP $=0.0$ ENDIE

\section{SETURB $=1.0$}

IF (TDBMAR $(7, N)$, GT. 0.0) THEN

$\mathrm{SR}=\operatorname{MAX}(\operatorname{TDBMAR}(7, \mathrm{~N})-\mathrm{DEPHGT}, \mathrm{DPMIN})$

DELFLM $=\operatorname{MAX}(D E P H G T, 0.0)$

TURBDEP = FTURB $($ VGAS, DPART, VISGAS, RHONOM, $\operatorname{TVOL}(2, N)$, RHOBLK . $\operatorname{TDBMAR}(3, N)$, SR, MMGAS, $\operatorname{TdBMAR}(8, N), \operatorname{DELFLM,~} \operatorname{SETURB})$ ENDIF

C * * THERMOPHORESIS COEFFICIENT

c

THRWDEP $=$ ETKRM $($ TVOL $(2, N)$, RHOBLK, VISGAS, MMGAS, DRART)

$c$

C * * DIfrusion

C

DIFEDER $=$ FDIFF $($ TVOL $(2, N)$, RHOBLK, VISGAS, KMGAS, DPART)

LINES 751-788 CHANGED FROM IF (NTYPE.EQ.1) THEN AKERNL = COREAV (ITERM+3)

ELSE IF (NTYPE.EQ.2) THEN

AKERNL = ZERO

ELSE IF (NTYPE.EQ.3) THEN

AKERNL COEEAV (ITERM+3)

END IF

IF (WCOND (J) . GR . ZERO) THEN

DIFEIO $=$ XDIFFI $\star$ WCOND $(J) /$ RHOBLK

$$
\text { ELSE }
$$

DIFETO $=$ WCOND (J) $/$ RHOSTM

$$
\text { END IF }
$$

AKERNZ = AKERNL + COEFAV (ITERM+I)

$+\quad+\operatorname{TGRAD}(J) \star \operatorname{COEFAV}($ ITERM +2$)$

$+\quad+$ DIFFIO

AKERNL $=\operatorname{MAX}$ (ZERO, AKRERNL)

$\operatorname{SUMH}(J)=\operatorname{AREAHS}(J)$ *AKERNL

SUMDEP $=S U M D E P+S U M H(J)$

IF (NTYPE . RQ . 3) SUMSET=SUMSET +AREAHS (J)

480

C

C

CONTINUE

POOL

\section{DIFFIO $=2 E R O$}

AKERNL = COEFAV (ITERM+3)

AKERNL $=$ AKERNL + COEFAV (ITERM+1)

$+$

$+$ + TGRADP *COEFAV (TTERM+2)

+ DIFFIO

AKERNL $=\operatorname{MAX}$ (ZERO, AKERNL)

SUMHP $=$ AREAP $*$ AKERNI

SUMDEP $=$ SUMDEP + SUMHP

SUMSET $=$ SUMSET+AREAP

ELOWTHRUS

AKERNX = $\operatorname{COEFAV~}($ ITERM+3) + CORFAV $($ ITERM+1)

AKRRNX = MAX (ZERO, AKRRNX)

SUMTRU $=$ ATHRU $\star A K C E R N X$

To

IF (NTYPE.EQ . 1) THEN

AKERNL = - GRAVDEP

ELSE IF (NTYPE.EQ.2) THEN

AKERNL = ZERO

ELSE TF (NTYPE .EQ .3) THEN

AKERNL = GRAVDEP

END IF

IF (WCOND (J) . GE . ZERO) THEN 
DIFEIO $=$ XDIFEI * FCOND(J) / RHOBLK

ELSE

DIFFIO $=$ FCOND (J) $/$ RHOSTM

END IF

c

AKERNL $=$ (AKERNL + DIFEDER

$+\quad+$ TGRAD (J) *THRMDEP

$+\quad+$ DIFFIO + TURBDEP) * SETURB

$+\quad+$ BENDDEP

AKERNL $=\operatorname{MAX}$ (ZERO, AKERNL)

SUMH $(J)=$ AREAHS $(J)$ *AKRRNL

SUMDEP $=S$ SUDEP + SUMH (J)

IF (NTYPE . EQ . 3) SUMSET $=$ SUMSET + AREAHS (J)

480

CONTINUE

poow

\section{DIFE IO=ZERO}

AKERNL = GRAVDEP

AKERNL $=$ AKERNL + DIFEDEP

$+$

TGRADP * THRMDEP

+ DIFFIO + TURBDER

AKERNL $=\operatorname{MAX}$ (ZERO, AKERNL)

SUMFP $=$ AREAP $\star$ AKERRNL

SUMDER = SUMDER+SUMHP

SUMSET $=$ SUMSET+AREAP

FLOWTHRUS

AKRERX = GRAYDEP + DIFFDEP

AKERNX = MAX (ZERO, AKERNX)

SUMTRU $=$ ATHRU $*$ AKCERNX
SUBROUTINE ADDED FOR LIQUID ENTRAINED AEROSOL RE-SUSPENSION

*DECK BUBDF

EUNCTION BUBDE (DPART, TP , PT, DT, RHOP, ZPOOL, APOOL, DMI)

SPARC CLONE FOR MRLCOR

- INCLUDE SC4405

4405 CONTATNS COEFEICIENTS FOR SPARC BUBBLE PHYSICS MODEL

DZZERO IS THE ZERO EFFICIENCY BUBBLE RISE HEIGHT

DZEFE IS THE FULL EFFICIENCY BUBBLE RISE HEIGHT IN FLOW JUNCTION HEIGHTS (FLHGT*DZEEE)

DTMPZR IS THR ZERO EFFICIENCY TEMPERATURE DIFEERENCE BETWEEN THE POOL TEMPERATURE AND THE SATURATION TEMPERATURE

DTMRZ IS THE FULL EEFICIENCY TEMPERATURE DIFFERENCE BETKEEN THE POOL TEMPERATURE AND THE SATURATION TEMPERATURE

PEFF IS THE RELATIVE HUMIDTTY OF THE STEAM AT THE SURFACE

COMON /F4405 / I4405, C4405(5), NA4405

COMMON /CP4405/ JP4405，IS4405(1)，IE4405(1)，MA4405

COMMON /CE4405/ CI4405

CHARACTER CI4405*19

EQUTVALENCE (C4405 (1),DZZERO) , ( C4405 (2),DZEFE) ,

1(C4405 (3), DTMPZR), (C4405 (4),DIEFE), (C4405 (5), PEEE)

c

C COMMON BLOCKS CONTAINING COBEFICIENTS, POINTERS, AND IDENTIFIERS FOR C ANALYTIC GUNCTION - SURFACE TENSION AS A FUNCTION OF TEMPERATURE:

C

C $\operatorname{SIGMA}(T)=A(1) *(A(2)+A(3) * T R) * T R * \star A(4)+A(5)$

C WHERE

c

T $=$ TEMPERATURE AND

$\mathrm{TR} \quad=A(6)-T / A(7)$.

C ELEMENTS: 
COMMON /E4000 / I4000, C4000(7) , NA4000 COMAON /CP4000/ JP4000, IS4000 (7) , IE4000 (7) , MA4000 COMMON /CF4000/ CI4000

CHARACTER CI $4000 * 120$

C

INCLUDE MPPRNO

COMMON BLOCK /MPPRNO/ HAS ORDERING OF PROPERTIES IN LIST GIVEN IN /MPPRNM/

COMMON /MPPRNO/ NUMENH, NUMTMP, NUMCPS, NUMTHC, NUMVIS, NUMDIF, NUMRHO

$\begin{array}{ll}\text { NUMENH }=1 & \text { ENTHALPY } \\ \text { NUMTMP }=2 & \text { TEMPERATURE } \\ \text { NUMCPS }=3 & \text { SPECIFIC HEAT } \\ \text { NUMTHC }=4 & \text { THERMAL CONDUCTIVITY } \\ \text { NUMVIS }=5 & \text { VISCOSITY } \\ \text { NUMDIF }=6 & \text { DIFFUSIVITY } \\ \text { NUMRHO }=7 & \text { DENSITY }\end{array}$

DIMRNSION XMASS (3)

C

ZERO $=0$. DO

HATF $=0.5 \mathrm{DO}$

C

CALL H2OSAT (0, TP, PWSAT, RHOW, RHOV, IERR)

$\operatorname{TPX}=\operatorname{MAX}(273 \ldots \operatorname{MIN}(\mathrm{XP}, 563)$.

$\operatorname{TRX}=\mathrm{C} 4000(6)-\mathrm{TPX} / \mathrm{C} 4000(7)$

SIGKA $=C 4000(1) *(C 4000(2)+C 4000(3) * T R X) * T R X * C_{4} 4000(4)$

1$$
+\mathrm{C4000(5)}
$$

STGMA $=$ MAX (SIGMA, 1.E-20)

NUMAMAT $=3$

XMASS (3) = HALF
CALL MPEVAL (NUMVIS, XMASS, ICNCRN, 3, 3, ' CVH', NUMMAT, PDUM, TP, VISVAP, IGERR)

NUMMAT $=1$

XMass (1) $=$ HatF

CALL MPEVAL (NUMVIS, XMASS, ICNCRN, 1, 1, ' CVH',

$P I=A \cos (-1.0)$

$G C=9.80665 D 0$

$\mathrm{DB}=2 .{ }^{\star} \mathrm{SQRT}$ (SIGMA/ (GC* (RHOW-RHOV))

$\mathrm{RB}=\mathrm{DB} / 2$.

$\mathrm{VB}=: \star \mathrm{DB} \star \star 3 / 6,0 \mathrm{DO}$

$\mathrm{SB}=6.000 * \mathrm{VB} / \mathrm{DB}$

G1 = GC*VISLIQ* (VISLIQ/SIGMA) **3/RHON

VR1 $=2, * R B * R B * G C *(R H O F-R H O V) /(12 . *$ VISLIQ $)$

REB = 2. *RHOW*VRI*RB/VISLIQ

IF (REB .IT . 2.0) THEN

VRISE $=$ VRI

GO TO 10

ENDIF

$\mathrm{VR2}=0.33 * G C * \star 0.75 *(\mathrm{RHOW} / \mathrm{VISLIQ}) * \star_{0} .52 * \mathrm{RB} * \star 1.28$

RBB $=2 . *$ RHOW*VR2 ".../VISLIO

$\operatorname{RE} 1=4.02 / G 1 * \star 0.214$

IF (REB .GE . 2.0 .AND. REB.LT .RE1) THEN

VRISE $=$ VR2

GO TO 10

$\operatorname{RE2}=3.1 / \mathrm{G} 1 * * 0.25$

VR3 $=1.35 *($ SIGMA $/$ RHOW/RB $) * * 0.5$

REB $=2 . *$ RHOW*VR3*RB/VISLIQ

IF (REB .GE .RE1 .AND. REB.LT.RE2) THEN

VRISE $=$ VR3

GO TO 10

\section{ENDIF}

VRISE $=1.53 *(G C *$ SIGMA $/$ RHOW $) * 0.25$

10 CONTINUE

VBUBL $=$ ABS (DML/ (DT*APOOt,*RHOV))

VBUBL = MAK (VRISE, VBUBL)

DECONTAMINATION DUE TO GRAVITATIONAL SETTLING 
$\mathrm{CM}=1.1$

VS $=$ RHOP * DPART**2 * CM * GC / (18.DO *VISVAP)

CENTRIFUGAL FORCES

VCM $=9 . \mathrm{DO}$ * VRISE * VRISE * VS $/(2 . \mathrm{DO}$ * DB * GC)

\section{BROWNIAN DIERUSION}

BOLTZ - JOULE / DEG K

BOLTZ $=1.38047 \mathrm{D}-23$

$C M=1.1$

DIFFUS $=$ BOLTZ * TP * CM /. (3.DO * DRART * PI * VISVAP)

VD $=2 . D O *$ SQRT (DIFFUS * VRISE / (RI * DB)

$A=v s$

$\mathrm{B}=\mathrm{VCM}$

$C=V D-V V$

$\mathrm{D}=\mathrm{B}+\mathrm{C}$

SUMVB $=V S+V D-V V$

STMVT $=-\mathrm{VS}+\mathrm{VD}-\mathrm{VV}$

$\operatorname{TERMX}=A * \mathrm{~A}+4.000 * D * \mathrm{~B}$

IF (TRRMX . LT .ZERO) THEN

DFALL $=1 . \mathrm{DO}$

GO TO 110

END IF

IF (B.EQ . ZERO) THEN

THETA1 $=0$. DO

THETA2 $=A \operatorname{COS}(-D / A)$

GO TO 120

BND IF

TOPN $=$ A - SORT (TERMX)

TOPR $=A+\operatorname{SQRT}($ TERMK)

$\mathrm{BOT}=2.0 \mathrm{DO} \star \mathrm{B}$
IF (ABS (TOPN/BOT) . LE. 1.0DO) THEN

THETAN $=A C O S$ (TOPN/BOT)

ELSB

THETAN $=0$. DO

END IF

IE (ABS (TOPR /BOT) . LE . 1. ODO) THEN THETAP $=A C O S$ (TOPP /BOT)

RLSE

THETAP $=0$. DO

END IF

THETA1 = MIN (THETAN, THETAP)

IF (SUMVB. GE . O.DO) THETA1 $=0 . \mathrm{DO}$

THETA2 $=$ MAX (THRTAN, THETAP)

IF (SUMVT.GE. O.DO) THETA2 $=\mathrm{PI}$

120

CONTINUE

TERM1 $=3.0 \mathrm{DO} / \mathrm{DB}$

$\operatorname{SIN12}=\operatorname{SIN}($ THETA1) * SIN (THETA1)

$\operatorname{sIN22}=\operatorname{sIN}($ THRTA2) * SIN (THETA2)

TERM2 $=0.500 * A * \operatorname{sIN22}$

TERM $=B * \cos ($ THETA2) $*(\operatorname{SIN} 22+2.0 D 0) / 3.0 \mathrm{DO}$

TERM4 $=\mathrm{C} * \cos ($ THETA2)

TERMS $=0.500 * A \star \operatorname{SIN12}$

TERM6 $=\mathrm{B} * \cos (\mathrm{THETA} 1) *(\operatorname{SIN} 12+2.0 \mathrm{DO}) / 3.0 \mathrm{DO}$

TERM7 $=\mathrm{C} * \cos$ (THETA1)

TERMAL $=$ TERM1 $*$ TTERM2 - TERM3 - TERM4

- TERM5 + TERM6 + TERM7)

EXPZ $=$ TERMAL/VBUBL

DFALL $=(1 .-\operatorname{EXP}(-\operatorname{EXPZ})) / \operatorname{EXPZ}$

110

DETOT = DEALI

IF (DFTOT.LT. 1. OD-5) DFTOT=1.OD-5

BUBDF $=$ DETOT 
SUBROUTINE ADDED FOR FOR INERTIAI, AND TURBULENCE DEPOSITION

FUNCTION FBEND (VE, DP, MU, RHOP, CHARL, NOFBNDS,

$$
\text { C. CONST }
$$

THETA, ACORAS, RADB, SF, GDEN, DE)

\section{*- INCLUDE CONST}

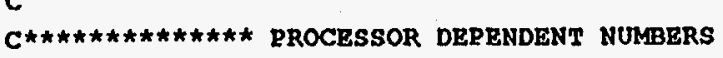

BIGMMP (BIGNM) = LARGEST POSITIVE (NEGATIVE) NUMBER

SMLNMP (SMLMMM) = SMALLEST POSITIVE (NEGATIVE) NUMBER

RNDNUM IS THE ROUNDOFF ASSOCIATED WITH THE NUMBER 1.

EXPMIN (EXPMAX) = LARGEST NEGATIVE (POSITIVE) MUMBER THAT CAN

BE USED AS AN ARGUMENT FOR THE EXP FUNCTION

XLMXX (XLOGMX) = LARGEST NUMBER THLAT CAN BE USED AS AN ARGUMENT

FOR THE LN (LOG) FUNCTION

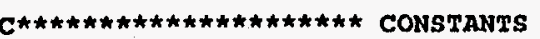

GRAVTY IS THE ACCELERATION OF GRAVITY (M/S**2) $=9.80665$ DO

ONE (ZERO, TWO, HALF) HOLDS THE NUMBER ONE (ZERO, TWO, HALF)

PI HOLD THE NUMBER PI= 3.141592653589793238462643383279DO

RGAS IS THE UNIVERSAI GAS CONSTANT (J/MOLE-K) $=8.3144100$

TCRIT HOLDS THE CRITICAL POINT OF WATER (K) $=647.24498900$

ZERODC HOLDS THE TEMPERATURE IN KELVIN EQUAL TO ZERO DEGREES

CENTIGRADE $(K)=273.1500$

ONETRD $=1 / 3, \quad$ TWOTRD $=2 / 3$

SBCON $=$ STEPFAN-BOLTZMANN CONSTANT (WATT $/ K * \star 2-K * \star 4)=5.67 \mathrm{D}-8$

COMMON /CONST/ BIGMR, BIGMM, SMLMMP, SMLNMM, RNDNUM, EXPMIN

1 , EXPMAX, XLMMX , XLOGMX, GRAVTY, ONE , PI , RGAS

2 , TCRIT, ZERO , ZERODC, ONETRD, TWOTRD, SBCON , THO

$$
\text { , HALF }
$$

SAVE,

REAL MU, NOFBNDS

$B=1 . /(3 . \star P I * M U \star D P)$

$\mathrm{XM}=\mathrm{RI} \mathrm{IDP} * * 3 * \mathrm{RHOP} / 6$.

$S=B * Y M * T H E T A * A B S$ (VF)

ERACDEP $=\operatorname{MIN}(1,0$, S/CHARL $)$
$R E=C H A R L \star A B S(V F) * G D E N / M U$

FRICI $=0.0791 / R E * * 0.25$

US $=\mathrm{ABS}(\mathrm{VE}) \star \mathrm{SQRT}\left(0.5\right.$ * FRICI) $^{-}$

$S P=S * U S * G D E N / M U$

$\mathrm{VB}=\mathrm{RHOP} *(\mathrm{DP} * \mathrm{VF}) * \star 2 /(18, * \mathrm{MU} * \mathrm{RADB})$

SFBEND $=$ FSTCK $(V B, D P$, RHOP，SF，VF，GDEN，MU，CHARL，SP，DF)

FBEND $=$ SEBEND*ABS (VF) *FRACDEP *ACORAS *NOFBNDS

C

RETURN

END

FUNCTION FTURB ( VE, DP, GVISC, RHOP, TGAS, GDEN,$$
\text { . }
$$

CHARI, SR, GMOLWT, SE, DE, SETURB)

C

*- INCLUDE RN1SIV

C

c

RN1 SIZE INDEPENDENY VARIABLES

COMAON/RN1SIV/RHONOM, ICOND, ICOEF, VISCOS, DENATR, FREEMN

+ CHI, GAMPA, FSLIP, STICK, PSAT, DELSAT, TURBDS,

+ TKGOP, DELDIF, DENSTY, ETHERM, VOLUME,

+ WTCONM, WTMOL, NB2A, NB2B, NB3, NB4, NDEPST, NGROW,

+ PGAS1, PGAS2, TGAS1, TGAS2, NCLSW, ICRLSE, NCLSBX *- INCLUDE CONST

C

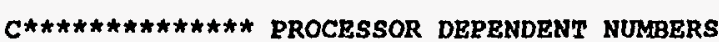

BIGNMP (BIGMMN) = LARGEST POSITIVE (NRGATIVE) NUMBER

SMLNMP (SMTMMM) $=$ SMALLEST POSITTVE (MEGATIVE) NUMBER

RNDNUM IS THE ROUNDOFF ASSOCIATED WITH THE NUMBER 1.

EXPMIN (EXPMAX) = LARGEST NEGATIVE (POSITIVE) NUMBER THAT CAN BE USED AS AN ARGUMENT FOR THE EXP FUNCTION

XLNMX (XLOGMX) = LARGEST NUMBER THAT CAN BE USED AS AN ARGUMENT FOR THE LN (LOG) FUNCTION

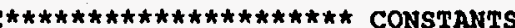

GRAVTY IS THR ACCELERATION OF GRAVITY (M/S**2) $=9.80665 \mathrm{DO}$ ONE (ZERO, TWO, HALF) HOLDS THE NUMBER ONE (ZERO, TKO, HALF) PI HOLD THE NUMBER PI= $3.141592653589793238462643383279 \mathrm{DO}$ RGAS IS THE UAIVERSAI GAS CONSTANT (J/MOLE-K) $=8.3144100$ TCRIT HOLDS THE CRITICAL, POINT OF WATER $(K)=647.244989 D 0$ ZERODC HOLDS THE TEMPERATURE IN KELVIN EQUAY TO ZERO DEGREES CENTIGRADE $(K)=273.15 D 0$ 
COMMON /CONST/ BIGMM, BIGNMM, SMLNMP, SMLNM, RNDNUM, EXPMIN 1 , EXPMAX, XINMX , XLOGMX, GRAVTY, ONE , PI , RGAS

2 , TCRIT , ZERO , ZERODC, ONETRD, TWOTRD, SBCON , TKO 3 , HALF

SAVE

REAL NU, IS, IB

DATA BCON/ 1.3806E-23/

$\mathrm{NU}=\mathrm{GVISC} / \mathrm{GDEN}$

$R E=$ CHARL $* A B S$ (VF) /NU

c

FRICI $=0.0791 / \mathrm{R} \approx \star \star 0.25$

US $=$ ABS (VE) *SQRT $(0.5 *$ ERICI)

$F A C=(R E-2000) /$.

IF (EAC.GT .1.0) FAC $=1.0$

IF (EAC.LT.0.0) FAC $=0.0$

C

C EVALUATE MRAN FREE PATH

c

FCHI $=\mathrm{CHI}$

GASMEP = GVISC $\star S O R T(1.89 \mathrm{E}-4$ *GMOLWT/TGAS) /GDEM

$A K N=2$. DO GASMFP $/ D P$

C LIMIT EXPONENT RANGE

ARGN $=A M T N 1$ (EXPMAX, 1.1/AKN)

BMOBIL $=1 .+A K N *($ FSLIP $+.4 * \operatorname{EXP}(-\operatorname{ARGN}))$

C
BPS $=\mathrm{BP}$

IF (TAUR.GT.10.) THEN

$S P=6.9$

USMF $=\operatorname{SQRT}\left(10 . \star_{\mathrm{NU}} /(\mathrm{XM} * \mathrm{~B})\right)$

$\mathrm{BP}=\operatorname{AMIN1}(0.45 * \mathrm{SR} * \mathrm{USM} / \mathrm{NU}, 30 .-\mathrm{SP})$

ENDIE

C

IF (BP+SP . LE . 5 .) THEN

$I B=24.2$

PHI1 $=\operatorname{MIN}(\mathrm{PHI},(\mathrm{BP}+\mathrm{SP}) / \mathrm{A})$

IS $=14.5 *($ FUNI $($ PHI $)-\operatorname{FUNI}($ PHI1 $)) /(\mathrm{DIFP} / \mathrm{NU}) \star \star(2 . / 3$. EISE

$I B=5 . \star_{A L O G}(25.2 /(\mathrm{BP}+\mathrm{SP}-4.8))$

IS $=0.0$

ENDIF

VR $=1 . /($ IB+IS)

IF (TAUR .LE. 10) 60 TO 20

C

VPWM $=$ VP
$B R=$ BPS

SP $=$ SPS

IF (TAUR . LT . 20.) THEN

$\mathrm{SP}=13.8$

USW2 $=\operatorname{SQRT}(20 . \star N U /(X M * B))$

$\mathrm{BP}=0.45 \star S R * U S W 2 / \mathrm{HU}$

$V P=0.55 *(1 .-\operatorname{ERF}(0.707 *(1,+B P / S P)))$

EXPON $=3.322 \star A L O G 10($ VPWM/VP) $*(1 .-A L O G 10$ (TAUP)) + ALOG10 (VPWM)

VP $=10 . * *_{\mathrm{EXPON}}$

60 TO 20

ENDIF

$10 \mathrm{VP}=0.55 \star(1 .-\mathrm{ERF}(0.707 *(1 .+\mathrm{BP} / \mathrm{SP})))$

20 FTURB $=$ FAC $* V P * U S$

* * CHECK FOR ADHESION

C

VD $=$ VR $\star U S$

SFTURB $=$ FSTCK $($ VD, DP, RHOP, SE, VF, GDEN, GVISC, CHARL, SP, DF) 


\section{RETURN}

END

FUNCTION FUNI (PAI)

SAVE

DATA SQR3 /1.73205/

THETA $=\left(2 .{ }^{*}\right.$ PHI -1.$) /$ SQR3

FUNI $=A L O G((1 .+P H I) * \star 2 /(1 .-P H I+P H I * \star 2)) / 6$.

\section{RETURN}

END

FUNCTION FSTCK (VRER, DR, RHOP, SE， VE，GDEN， GVISC

CHARL, SP, DELW)

*- INCLUDE CONST

$c$

$C \star \star \star \star \star \star \star \star \star \star \star \star \star \star \star * \star$ PROCESSOR DEPENDENT NUMBERS

BIGNMP (BIGMM) = LARGEST POSITIVE (NEGATIVE) NUMBER

SMLNMP (SMLMMM) = SMALLEST POSITIVE (REGATIVE) NUMBER

RNDNUM IS THE ROUNDOFE ASSOCIATED WITH THE NUMBER 1 .

EXPMIN (EXPMAX) = LARGEST NEGATIVE (POSITIVE) NUMBER THAT CAN

BE USED AS AN ARGUMENT FOR THE EXP FUNCTION

XLMMX (XLOGMX) = LARGEST NUMBER THAT CAN BE USED AS AN ARGUMENT

FOR THE LN (LOG) FUNCTION

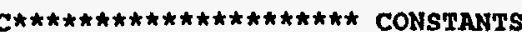

GRAVTY IS THE ACCELBRATION OF GRAVITY (M/S**2) $\approx 9.8066500$ ONR (ZERO, TWO, HALF) HOLDS THE NUMBER ONE (ZERO, TKO, HALF)

$P I$ HOLD THE NUMBER $P I=3.141592653589793238462643383279 \mathrm{DO}$

RGAS IS THR UNIVERSAL GAS CONSTANY (J/MOLE-K) $=8.3144100$

TCRIT HOLDS THE CRITICAL POINT OF WATER (K) $=647.244989$ DO

ZERODC HOLDS THE TEMPERATURE IN KELVIN ERUAL TO ZERO DEGREES

CENTIGRADE $(K)=273.15 \mathrm{DO}$

ONETRD $=1 / 3, \quad$ TWOTRD $=2 / 3$

SBCON $=$ STEPEAN-BOLTZMANN CONSTANT (WATT/M**2-K**4) $=5.67 D-8$

COMMON /CONST/ BIGNMP, BIGNMM, SMLNMP, SMLMM, RNDNUM, EXPMIN

- EXPMAX, XLMMX , XLOGMX, GRAVTY, ONE , PI , RGAS

- TCRIT , ZERO , ZERODC, ONETRD, TKOTRD, SBCON , TWO

- HALF

SAVE

DATA ER/ $0.1 /$

DATA GAMVF/ $0.04 /$

DATA SIGMAW/ $97 . \mathrm{E}-3 /$

DATA ETAF/ 5.05E-2/

* Check for excess MOMENTUM

(USE WATER SURFACE TENSION $X$ STICKING FACTOR

+ VANDER WALLS FORCE)

$\mathrm{XM}=\mathrm{PI} * \mathrm{DP} * * 3 * \mathrm{RHOP} / 6$.

$V C=\operatorname{SQRT}(0.25 \star P I * D P \star \star 2 *(4 . \star S E \star S I G M A W+1.5 \star F R \star G A M V E) / X M)$ $+0.75 * P I * D P * S F * E T A W * D E L W / X M$

VPAR $=\operatorname{SQRT}(\operatorname{MAX}(0, . \mathrm{VC} \star \star 2-V P E R \star \star 2))$

VPMX $=-3.05+5 . \star A L O G(S P)$

$\mathrm{VP}=\operatorname{MIN}(\mathrm{VPMK}, \mathrm{VPAR} / \mathrm{US})$

IF (VP.LE.5.0) THEN

$Y \mathbf{P}=\mathrm{VP}$

ELSE

$Y P=\operatorname{MIN}(S P, \operatorname{EXP}((\mathrm{VP}+3.05) / 5.1)$

ENDIF

FSTCK $=\operatorname{YP} / \mathrm{MAX}(S P, 1 . \mathrm{E}-6)$

C

RRTURN

END 
SUBROUTINES ADDED FOR GAS COMPOSITION IN DEPOSITION VELOCITIES

FUNCTION FGRAV (TGAS, GDEN, GVISC, GMOLWT, DPART, RHOP)

* INCLUDE RN1SIV

$\mathrm{c}$

$\mathrm{C}$

RN1 SIZE INDEPENDENT VARIABLES

COMMON/RN1SIV/RHONOM, ICOND, ICOEF, VISCOS, DENAIR, FREEMN,

+ CHI, GAMAA, ESLIP, STICK, PSAT, DELSAT, TURBDS,

+ TKGOP, DELDIF, DENSTY, ETHERM, VOLUME,

+ WTCONM, KTMOL, NB2A, NB2B, NB3, NB4, NDEPST, NGROW,

+ PGas1, PGAS2, TGAS1, TGAS2, NCLSH, ICRLSE, NCLSBX

*- INCLUDE CONST

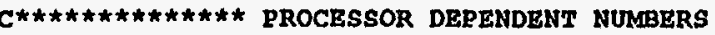

BIGNM (BIGMM) = LARGEST POSITIVE (NEGATIVE) NUMBER

SMLNMP (SMLNMM) = SMALLEST POSITIVE (NEGATIVE) NUMBER

RNDNUM IS THE ROUNDOFF ASSOCIATED WITH THE NUMBER 1.

EXPMIN (EXPMAX) = LARGEST NEGATIVE (ZOSITIVE) NUMBER TLAT CAN

BE USED AS AN ARGUMENT EOR THE EXP FUNCTION

XCMMX (XLOGMX) = IAARGEST NUMBER THAT CAN BE USED AS AN ARGUMENT FOR THE LN (LOG) FUNCTION

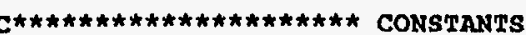

GRAVTY IS THE ACCELERATION OF GRAVITY (M/S**2) $=9.8066500$

ONE (ZERO, TWO, HALF) HOLDS THE NUMBER ONE (ZERO, TWO, HALF)

PI HOLD THE NUMBER PI= 3.14259265358979323846264338327900

RGAS IS THE UNIVERSAL GAS CONSTANT (J/MOLE-K) $=8.3144100$

TCRIT HOLDS THE CRITICAL POINT OF WATER (K) $=647.24498900$

ZERODC HOLDS THE TEMPERATURE IN KELVIN EQUAL TO ZERO DEGREES

CENTIGRADE $(K)=273.15 D 0$

ONETRD $=1 / 3, \quad$ TWOTRD $=2 / 3$

SBCON $=$ STEPFAN-BOLTZMANN CONSTANT (WATT/M**2-K**4) $=5.67 \mathrm{D}-8$

COMAON /CONST/ BIGMM, BIGNM, SMLNMP, SMLMMM, RNDNUM, EXPMIN

$$
\text { - EXPMAX, XINMX , XLOGMX, GRAVTY, ONE , PI , RGAS }
$$

; TCRIT , ZERO , ZERODC, ONETRD, TWOTRD, SBCON , TWO

, HALF
EVALUATE MEAN FREE PATH

FCHI $=\mathrm{CHI}$

GASMFP $=$ GVISC*SQRT $(1.89 E-4$ *GMOLWT/TGAS $) /$ GDEN

AKON $=2$. DO*GASMFP /DPART

\section{LIMTT EXPONENT RANGE}

ARGN=AMIN1 (EXPMAX, 1.1/AKNN)

BMOBIL $=1$. $+A K N *($ FSLIP + . 4 EXP $(-A R G N))$

EIND PARTICLE SETTLING SPEED ACCOUNTING FOR SLIP CORRECTION

ACCELERATION OF GRAVITY $/ 18=5.44444444 D-01$

VSET $=5.44444444 \mathrm{D}-01$ * BMOBIL * DPART * DPART *

\# (RHOP - GDEN) / (GVISC*FCHI)

FGRAV = VSET

RETURN

END

FUNCTION FTHRM (TGAS, GDEN, GVISC, GMOLKT, DEART)

THIS ROUTINE CALCULATES THE DEPOSITION COEFFICIENTS DUE TO THERMORHORESIS.

REFRRENCES: GIESEKE, J.A., LEE, K.พ. AND REED, I.D. 'HAARM-3 USERS MANUAL,' BMI-NUREG-1991 (1978), BROCK, J.R. 'ON THE THEORY OF THERMAL FORCES ACTING ON AEROSOL PARTICLES,' J. COLLOID INTERFACE SCIENCE, VOL.17, 768 (1962)

\section{INCLUDE RN1SIV}

RN1 SIZE INDEPENDENT VARIABLLS

COMMON/RN1SIV/RHONOM, ICOND, ICOEF, VISCOS, DENAIR, FREEMN,

+ CHI, GAMMA, FSLIP, STICK, PSAT, DELSAT, TUREDS,

+ TKGOP, DELDIF, DENSTY, ETHERM, VOLUME

+ WICONM, WIMOL, NB2A, NB2B, NB3, NB4, NDEPST, NGROW, 
C

*- INCLUDE CONST

C

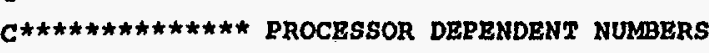

BIGNMP (BIGMMM) = LARGEST POSITIVE (NEGATIVE) NUMBER

SMLNMP (SMLNM) = SMALIEST POSITIVE (NEGATIVE) NUMBER

RNDNUM IS THE ROUNDOFE ASSOCIATED WITH THE NUMBER 1.

EXPMIN (EXPMAX) = ILARGEST NEGATIVE (POSITIVE) NUMBER THAT CAN

BE USED AS AN ARGUMENT FOR THE EXP FUNCTION

XLNMX (XLOGNX) = LARGEST NUMBER THAT CAN BE USED AS AN ARGUMENT FOR THR LN (LOG) FUNCTION

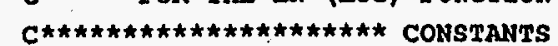

GRAVTY IS THE ACCELRRATION OF GRAVITY (M/S**2) $=9.80665$ DO

ONE (ZERO, TWO, HALF) HOLDS THE NUMBER ONE (ZERO, TWO, HALF)

$P I$ HOLD THE NUMBER $P I=3.141592653589793238462643383279 \mathrm{DO}$

RGAS IS THE UNIVERSAL GAS CONSTANT (J/MOLE-K) $=8.31441 \mathrm{DO}$

TCRIT HOLDS THE CRITICAL POINT OF WATER (K) $=647.24498900$

ZERODC HOLDS THE TEMPERATURE IN KELVIN EQUAL TO ZERO DEGRES

CENTIGRADE $(K)=273.15 D 0$

ONETRD $=1 / 3, \quad$ TKOTRD $=2 / 3$

SBCON $=$ STEPFAN-BOLTZMANN CONSTANT $($ WATT/M**2-K**4) $=5.67 D-8$

c

COMMON /CONST/ BIGNMP, BIGNMM, SMLNMP, SMLNMM, RNDNUM, EXPMIN

1 , EXPMAX, XLMMX , XLOGMX, GRAVTY, ONE , PI , RGAS

2 , TCRIT , ZERO , ZERODC, ONETRD, TKOTRD, SBCON , TWO

c

*-

C

SAVE

FCHI $=$ CHI

GASMFR $=$ GVISC*SQRT (1.89E-4*GMOLWT/TGAS)/GDEN

AKN $=2$. DO $*$ GASMFP/DPART

c

C LIMTT EXPONENT RANGE

C

ARGN=AMTN1 (EXPMAX, 1.1/ ARN)

BMOBIL $=1$. + AKON* (FSLIP + . 4*BXP (-ARGN) )

VTHRMI $=1.5$ *GVISC *BMOBIL* (FTHERM*AKN+TKGOP) / (FCHI*GDEN *

\& TGAS* $(1 .+3 . \star F S L I R \star A K N) *(1 .+2 . *($ FTHERM*AKN+TKGOP) )
FTHRM $=$ VTHRMI,

RETURN

END

FUNCT YON FDIFE (TGAS, GDEN, GVISC, GMOLWT, DPART)

THIS ROUTINE CALCULATES THE DEPOSITION COEFRICIENTS DUE TO GRAVITY, DIFEUSION AND THERMOPHORESIS.

REFERENCES: GIESEKE, J.A., LEE,K.W. AND REED, L.D. ' HAARM-3 USERS MANUAL,' BMI-NUREG-1991 (1978), BROCK, J.R. 'ON THE THEORY OF THERMAL FORCES ACTING ON ARROSOL PARTICLRS,' $J$. COLLOID INTEREACE SCIENCE, VOL.17, 768 (1962)

*- INCLUDE RH1SIV

RN1 SIZE INDEPENDENT VARIABLES

COMMON/RN1SIV/RHONOM, ICOND, ICOEF, VISCOS, DENAIR, FREEMN,

+ CHI, GAMMA, FSLIP, STICK, PSAT, DELSAT, TURBDS ,

+ TKGOP, DELDIF, DENSTY, ETHERM, VOLUME,

+ KTCONM, WTMOL, NB2A, NB2B, NB3, NB4, NDEPST, NGROW,

+ PGAS1, PGAS2, TGAS1, TGAS2, NCLSW, ICRLSE, NCLSBX

*- INCLUDE CONST

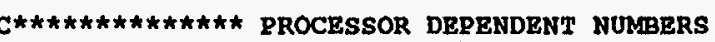

BIGMMP (BIGMMM) = LARGEST POSITIVE (NEGATIVE) NURBER

SMLNMP (SMLNMM) = SMALLEST POSITIVE (NEGATIVE) NUMBER

RWDNUM IS THE ROUNDOFF ASSOCIATED WITH THE NUMBER 1.

EXPMIN (EXPMAX) = LAARGEST NEGATIVE (POSITIVE) NUMBER THAT CAN

BE USED AS AN ARGUMRNT FOR THE EXP FUNCTION

XLMMX (XIOGMX) = LLARGEST NUMAER THAT CAN BE USED AS AN ARGUMENT

FOR THE LiN (LOG) FUNCTION

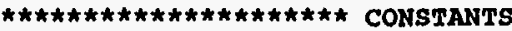

GRAVTY IS THE ACCELERATION OF GRAVITY (M/S**2) $=9.8066500$

ONE (ZRRO, TWO, HALF) HOLDS THE NUMBER ONE (ZERO, TWO, HALF)

$P I$ HOLD THE NUMBER $P I=3.141592653589793238462643383279 D 0$

RGAS IS THE UNIVERSAL GAS CONSTANT (J/MOLE-K) $=8.3144100$

TCRIT HOLDS THE CRITICAL ROINT OF WATER $(\mathrm{K})=647.244989 \mathrm{DO}$

ZERODC HOLDS THE TEMPERATURE IN KELVIN EQUAL TO ZERO DEGREES

CENTIGRADE $(K)=273.15 \mathrm{DO}$

ONETRD $=1 / 3, \quad$ TWOTRD $=2 / 3$

SBCON $=$ STEPFAN-BOLTZMANN CONSTANT $($ WATT $/ M \star * 2-K \star \star 4)=5.67 D-8$ 
COMMON /CONST/ BIGMP, BIGMM, SMLNMP, SMLNMM, RNDNUM, EXPMIN

1 , EXPMAX, XINMX , XLOGMX, GRAVTY, ONE , PI , RGAS

2 , TCRIT , ZERO , ZERODC, ONETRD, TKOTRD, SBCON , TKO

3 , HALF

C

*-

SAVE

C

\section{FCHI $\approx$ CHI}

GASMFP \# GVISC*SQRT (1.89E-4*GMOLWT/TGAS) /GDEN

$A K A=2 . D O * G A S L F P / D P A R T$

C

LIMTT EXPONENT RANGE

c

ARGN $=$ AMIN1 $($ EXPMAX, 1 . 1/AKN $)$

BMOBIL $=1 .+\mathrm{AKN} *$ (FSLIP+ . 4 *EXP (-ARGN))

$D I F=(1.46 \mathrm{Z}-24 * \mathrm{TGAS} * \mathrm{BMOBIL} /($ GVISC*FCHI*DPART $)) / D E L D I F$

FDIFF $=\mathrm{DIF}$

RETURN

END 